\title{
Understanding Earnings, Labor Supply, and Retirement Decisions
}

Xiaodong Fan, Ananth Seshadri, and Christopher Taber 


\title{
Understanding Earnings, Labor Supply, and Retirement Decisions
}

\author{
Xiaodong Fan \\ University of New South Wales \\ Ananth Seshadri \\ University of Wisconsin-Madison \\ Christopher Taber \\ University of Wisconsin-Madison \\ September 2017 \\ Michigan Retirement Research Center \\ University of Michigan \\ P.O. Box 1248 \\ Ann Arbor, MI 48104 \\ www.mrrc.isr.umich.edu \\ (734) 615-0422
}

\section{Acknowledgements}

The research reported herein was performed pursuant to a grant from the U.S. Social Security Administration (SSA) funded as part of the Retirement Research Consortium through the University of Michigan Retirement Research Center Award RRC08098401-09. The opinions and conclusions expressed are solely those of the author(s) and do not represent the opinions or policy of SSA or any agency of the federal government. Neither the United States government nor any agency thereof, nor any of their employees, makes any warranty, express or implied, or assumes any legal liability or responsibility for the accuracy, completeness, or usefulness of the contents of this report. Reference herein to any specific commercial product, process or service by trade name, trademark, manufacturer, or otherwise does not necessarily constitute or imply endorsement, recommendation or favoring by the United States government or any agency thereof.

\section{Regents of the University of Michigan}

Michael J. Behm, Grand Blanc; Mark J. Bernstein, Ann Arbor; Shauna Ryder Diggs, Grosse Pointe; Denise Ilitch, Bingham Farms; Andrea Fischer Newman, Ann Arbor; Andrew C. Richner, Grosse Pointe Park; Ron Weiser, Ann Arbor; Katherine E. White, Ann Arbor; Mark S. Schlissel, ex officio 


\title{
Understanding Earnings, Labor Supply, and Retirement Decisions
}

\begin{abstract}
We develop and estimate a model in which individuals make decisions on consumption, human capital investment, labor supply, and retirement. Unlike all previous work, our model allows both an endogenous wage process (which is typically assumed exogenous in the human capital and earnings dynamics literature). In addition, we introduce health shocks. We estimate the model and match the life-cycle profiles of wages, hours and retirement from SIPP data. We analyze the impact of health shocks on retirement, as well as the effect of changes in payroll taxes and increases in the Normal Retirement Age on labor force participation of older Americans.
\end{abstract}

\section{Citation}

Fan, Xiaodong, Ananth Seshadri, and Christopher Taber. 2017. "Understanding Earnings, Labor Supply, and Retirement Decisions.” University of Michigan Retirement Research Center (MRRC) Working Paper, WP 2017-367. Ann Arbor, MI.

http://mrrc.isr.umich.edu/wp367/ 


\section{Introduction}

Understanding retirement behavior is fundamental to analyzing the impact that policy changes will have on the well-being of old Americans. How important are health shocks in triggering retirement? What are the effects of extending the Normal Retirement Age on the labor force participation rate of old workers? To what extent would the elimination of the payroll tax above the full retirement age induce people to stay in the workforce longer? These are important questions and we seek to answer them in a framework in which retirement and earnings profile are endogenous.

The retirement literature typically takes the wage process as given and estimates the date of retirement. One typically sees wages fall substantially before retirement. Raw wages for individuals who work fall by over $25 \%$ between age 55 and 65 . In the retirement literature, this trend is extremely important for explaining retirement behavior. If workers do not make much, it is economically efficient for them to retire. A policy such as extending the retirement age to 70 could have very negative consequences on these workers who have low wages at this point in their lives. Lifecycle human capital models (Ben-Porath (1967)) provide a very different perspective. They take the retirement date as given, but model the formation of the wage process. Young workers optimally choose to invest in their human capital which results in wage growth. Wages then level off in mid-career. As workers approach retirement, they optimally stop investing and allow their skills to depreciate. This leads to a fall in wages right before retirement. One can see that these models have very different predictions about changes in the retirement age. In the first type of model, workers will see substantial declines in their wages and we may be forcing workers to work at very low wages. By contrast, in the human capital model investment will adjust. If the retirement age is extended to 70, workers will invest in human capital until a later age. Thus, rather than see wages start to fall at age 55, this would likely be delayed until the early sixties. Endogenizing the wage process could lead to very different welfare effects when extending the retirement age.

Quite surprisingly, aside from the seminal work in Heckman $(1976,1975)$, there has been little effort integrating these two important paradigms. This paper attempts to fill this void by estimating a life-cycle model wherein the wage, labor supply and retirement choices are rationalized in one unified setting. After endogenizing both labor supply and human capital, this model is rich enough to explain the life-cycle patterns of both wages and labor supply, with a focus on wage patterns and retirement at the end of working life.

Specifically, we develop and estimate a Ben-Porath type human capital model in which workers undertake consumption, human capital investment, and labor supply decisions. 
We estimate the model using Indirect Inference, matching the wage and hours profiles of male high school graduates from the Survey of Income and Program Participation (SIPP). With a parsimonious life-cycle model in which none of the parameters explicitly depend upon age or experience, we are able to replicate the main features of the data. In particular we match the large increase in wages and very small increase in labor supply at the beginning of the life-cycle as well as the small decrease in wages but very large decrease in labor supply at the end of the life-cycle.

While our baseline model does not incorporate health, we estimate a specification that allows the taste for leisure to depend on health and for this effect to increase with age. Surprisingly, such an "enhanced" model does not significantly improve the fit of the lifecycle patterns of wage and labor supply of the SIPP data. We also show that even within this model that allows a direct and flexible effect of health on labor supply, health plays a relatively minor role in the decline in labor supply late in life.

We use the estimated model to simulate the impacts of various Social Security policy changes. Much serious work has been developed to quantitatively estimate the economic consequences of an aging population and evaluate the remedy policies (Gustman and Steinmeier, 1986; Rust and Phelan, 1997; French, 2005; French and Jones, 2011; Haan and Prowse, 2014). They model retirement as a result of combinations of declining wages, increasing actuarial unfairness of the Social Security and pension system, and increasing tastes for leisure. However, there is a major difference between our model and the previous retirement literature. Prior work typically takes the wage process as given and focuses on the retirement decision itself. For example, when conducting the counterfactual experiment of reducing the Social Security benefit by $20 \%$, the previous literature takes the same age-wage profile as in the baseline model and re-estimates the retirement behavior under the new environment. As the wage has already been declining significantly and exogenously approaching the retirement age, under the new policy working is still less likely attractive for many workers. However, as we show in our model, less generous Social Security benefits result in higher labor supply later in the life-cycle, so workers adjust their investment over the life-cycle, which results in a higher human capital level as well as higher labor supply earlier. On average the observed wage levels are $5 \%$ higher between 65 and 80 . Over the whole life-cycle, observed average yearly wages, total labor income, and total labor force participation rates increase by $1.5 \%, 2.17 \%$, and $1.57 \%$, respectively. By contrast, in the model with exogenous human capital, the percentage increases in yearly wages, total labor income and total labor supply are less significant, by $0.2 \%, 1.26 \%$, and $1.31 \%$, respectively. The differences are more dramatic in the experiments in which we remove the Social Security system, with the exogenous model 
underestimating most effects.

\section{Relevant Literature}

Human capital models have been widely accepted as a mechanism to explain lifecycle wage growth as well as the labor supply and income patterns. In his seminal paper, Ben-Porath (1967) develops the human capital model with the idea that individuals invest in their human capital "up front." In what follows we often use the term- "human capital model" to mean "Ben-Porath model." Heckman $(1975,1976)$ further extends the model and present more general human capital models in which each individual makes decisions on labor supply, investment and consumption. In both papers, each individual lives for finite periods and the retirement age is fixed. In their recent paper, Manuelli et al. (2012) calibrate a Ben-Porath model to include the endogenous retirement decision. All three models are deterministic.

Relative to the success in theory, there hasn't been as much work empirically estimating the Ben-Porath model. Mincer (1958) derives an approximation of the Ben-Porath model and greatly simplifies the estimation with a quadratic in experience, which is used in numerous empirical papers estimating the wage process (Heckman et al. (2006)). Early work on explicit estimation of the Ben-Porath model was done by Heckman $(1975,1976)$, Haley (1976), and Rosen (1976). Heckman et al. (1998a) is a more recent attempt to estimate the Ben-Porath model. They utilize the implication of the standard Ben-Porath model where at old ages the investment is almost zero. However, this implication does not hold any more when the retirement is uncertain, where each individual always has an incentive to invest a positive amount in human capital. Browning et al. (1999) survey much of this literature. ${ }^{1}$

Another type of human capital model, the learning-by-doing model, draws relatively more attention in empirical work. In the learning-by-doing model human capital accumulates exogenously, but only when an individual works. Thus workers can only impact their human capital accumulation through the work decision. In these models, the total cost of leisure is not only the direct lost earnings at the current time, but also includes the additional lost future earnings from the lower level of human capital. Shaw (1989) is among the first to empirically estimate the learning-by-doing model, using the PSID model and utilizing the Euler equations on consumption and labor supply with translog utility. Keane and Wolpin (1997) and Imai and Keane (2004) are two classic examples of re-

\footnotetext{
${ }^{1}$ Other more recent work includes Taber (2002), who incorporates progressive income taxes into the estimation, and Kuruscu (2006), who estimates the model nonparametrically.
} 
search that directly estimate a dynamic life-cycle model with learning-by-doing. Blundell et al. (2015) is a more recent example. These papers assume an exogenously fixed retirement age. Wallenius (2009) points out that such a learning-by-doing model does not fit the pattern of wages and hours well at old ages. ${ }^{2}$ Heckman et al. (2003) study the potential effects of wage subsidies on skill formulation by comparing on-the-job training models with learning-by-doing models. They simulate the effects of the 1994 EITC schedule for families with two children and find evidence that EITC lowers the long-term wages of people with low levels of education. They find that the learning-by-doing model predictions of the EITC policy effects fit the actual changes better than the Ben-Porath style model.

There is a large and growing literature on many aspects of retirement. In these models, typically retirement is induced either by increasing utility toward leisure (e.g. Gustman and Steinmeier, 1986) or increasing disutility toward labor supply (e.g. Blau, 2008). Haan and Prowse (2014) estimate the extent to which the increase in life expectancy affects retirement. Blau (2008) evaluates the role of uncertain retirement ages in the retirementconsumption puzzle.

Retirement can also be induced by declining wages at old ages and/or fixed costs of working. Rust and Phelan (1997) estimate a dynamic life-cycle labor supply model with endogenous retirement decisions to study the effect of Social Security and Medicare in retirement behavior. French (2005) estimates a more comprehensive model including savings to study the effect of Social Security and pension as well as health in retirement decisions. French and Jones (2011) evaluate the role of health insurance in shaping retirement behavior. Casanova (2010) studies the joint retirement decision among married couples. Prescott et al. (2009) and Rogerson and Wallenius (2010) present models where retirement could be induced by a convex effective labor function or fixed costs.

In all the retirement literature listed above-theoretical or empirical-the wage process is assumed to be exogenous. That is, even when the environment changes while conducting counterfactual experiments, for example changing the Social Security policies, the wage process is kept the same and only the response in the retirement decision is studied.

\footnotetext{
${ }^{2}$ However, if one interprets the hourly wages as labor income and hours as labor force participation rates (since there is no participation decision in their model), the fit in Imai and Keane (2004) would be improved at older ages.
} 


\section{Model}

We present and estimate a Ben-Porath style human capital model with endogenous labor supply and retirement in which individuals choose consumption, human capital investment, and labor supply (including retirement as a special case). For simplicity we suppress the individual subscript $i$ for all variables. We allow for heterogeneity in some of the parameters when estimating the model. We delay discussion of this to Section 4.2 for expositional convenience.

\subsection{Set-up}

Time is discrete. Each individual lives from period $t=0$ to $t=T$. At the beginning of the initial period, each individual is endowed with an initial asset $A_{0} \in \mathbb{R}$ and an initial human capital level $H_{0} \in \mathbb{R}^{+}$.

We model the extensive margin of labor supply, so at each period the individual decides either to work or not. The flow utility at period $t$ is

$$
u_{t}\left(c_{t}, \ell_{t}, \gamma_{t}\right)=\frac{c_{t}^{1-\eta_{c}}}{1-\eta_{c}}+\gamma_{t} \ell_{t}
$$

where $c_{t}$ is consumption and $\ell_{t} \in\{0,1\}$ is leisure. The coefficient $\gamma_{t}$ represents taste for leisure. We allow for shocks in $\gamma_{t}$ which is assumed to be an i.i.d. random variable for each individual. ${ }^{3}$

If an individual chooses to work, he decides on how much time, $I_{t}$, to invest in human capital and spends the rest, $1-I_{t}$, at effective (or productive) work from which the wage income is earned. Human capital is produced according to the production function

$$
H_{t+1}=(1-\delta) H_{t}+\xi_{t} \pi I_{t}^{\alpha} H_{t}^{\alpha_{H}}
$$

where $H_{t}$ is the human capital level at period $t$. The $\xi_{t}$ is an idiosyncratic shock to the human capital innovation. If an individual chooses not to work, he does not invest in human capital (so $I_{t}=0$ ) and human capital depreciates at rate $\delta$.

The labor market is perfectly competitive. We normalize the rent of human capital to one so that the wage for the effective labor supply equals the human capital $H_{t}$. Thus pre-tax labor income at any point in time is $H_{t}\left(1-\ell_{t}\right)\left(1-I_{t}\right)$.

\footnotetext{
${ }^{3} \mathrm{~A}$ key part of our exercise is that we do not allow $\gamma_{t}$ to vary systematically across age. We describe the exact process in the next subsection. The two terms - "period" and "age" - are used interchangeably throughout the paper.
} 
While we have tried to keep the basic model as simple as possible, the social security system in the U.S. is such a crucial part of the retirement decision that we incorporate it into the model. We model the social security enrollment decision as a one time decision. Once a person turns 62 they can start claiming social security and once they have started claiming, they continue to collect benefits until their death. We will let $s s a_{t}$ denote a binary decision variable indicating whether a person starts claiming at period $t$ and let $s s_{t}$ be a state variable indicating whether a person began claiming prior to period $t$. Since claiming is irreversible, once $s s_{t}=1$ then $s s a_{t}$ is no longer a relevant choice variable. Thus the law of motion can be written as

$$
\begin{aligned}
s s_{0} & =0 \\
s s_{t} & =\max \left\{s s_{t-1}, s s a_{t-1}\right\} .
\end{aligned}
$$

The claiming decision $\left(s s a_{t}\right)$ is made separately from the labor force participation decision $\left(\ell_{t}\right)$ so that one can receive the social security benefit while working (subject to applicable rules such as the earnings test).

Once they have begun claiming, an individual collects benefits $s s b_{t}$ which are a function of the claiming age and the Average Indexed Monthly Earnings $\left(A I M E_{t}\right)$. In practice we approximate the AIME and use the social security rules as of 2004. Details are in the Appendix. This is incorporated into the budget constraint

$$
A_{t+1}=(1+r) A_{t}+Y_{t}\left(H_{t}\left(1-\ell_{t}\right)\left(1-I_{t}\right), s s b_{t}\right)-c_{t}+\tau_{t}
$$

where $A_{t}$ stands for asset and $r$ is the risk free interest rate. $Y_{t}(\cdot, \cdot)$ is the after-tax income which is a function of wage income, the social security benefit $s s b_{t}$, and the tax code. Government transfers, $\tau_{t}$, provide a consumption floor $\underline{c}$ as in Hubbard et al. (1995) so

$$
\tau_{t}=\max \left\{0, \underline{\mathrm{c}}-\left((1+r) A_{t}+Y_{t}-\underline{\mathrm{A}}_{t+1}\right)\right\},
$$

where $\underline{A}_{t+1}$ is the asset lower bound at period $t+1 .^{4}$

Life ends at the end of period $T$ and each individual values the bequest he will leave. It takes the form

$$
b\left(A_{T+1}\right)=b_{1} \frac{\left(b_{2}+A_{T+1}\right)^{1-\eta_{c}}}{1-\eta_{c}}
$$

\footnotetext{
${ }^{4}$ We define the asset lower bound as the amount that each individual can pay back for sure before death, as in Aiyagari (1994). Since the probability of not working at each period is positive, the lower bound is characterized by the nonnegative consumption and the bequest function specified below, which is $\underline{\mathrm{A}}_{t}=-b_{2} /(1+r)^{T-t+1}$.
} 
where $b_{1}$ captures the relative weight of the bequest motive and $b_{2}$ determines its curvature as in DeNardi (2004).

\subsection{Solving the model}

Two shocks affect individuals: the leisure shock, $\gamma_{t}$, and the human capital innovation shock, $\xi_{t}$. The timing of the model works as follows: at the beginning of each period $\gamma_{t}$ is realized by the agent. He then simultaneously chooses consumption, labor supply, human capital investment, and social security application when relevant. After these decisions are made, the human capital innovation shock $\xi_{t}$ is realized, which determines the human capital level in the following period. Both $\gamma_{t}$ and $\xi_{t}$ are i.i.d. shocks from the perspective of the agents-so agents have no private information about their value prior to their realizations.

The recursive value function can be written as

$$
V_{t}\left(X_{t}, \gamma_{t}\right)=\max _{c_{t}, \ell_{t}, I_{t}, s s a_{t}}\left\{u_{t}\left(c_{t}, \ell_{t}, \gamma_{t}\right)+\beta E\left[V_{t+1}\left(X_{t+1}, \gamma_{t+1}\right) \mid X_{t}, c_{t}, \ell_{t}, I_{t}, s s a_{t}\right]\right\}
$$

where $X_{t}=\left\{A_{t}, H_{t}, A I M E_{t}, s s_{t}\right\}$ is the vector of state variables. The expectation is over the leisure shock in $\gamma_{t+1}$ and the human capital innovation $\xi_{t}$.

The solution to the agent's problem each period is done in two stages. We first solve for the optimal choices conditional on the labor supply decision and then we determine the labor supply decision.

The optimal consumption $\mathcal{C}_{t, 0}\left(X_{t}\right)$, investment $\mathcal{I}_{t, 0}\left(X_{t}\right)$, and social security claiming $\mathcal{S} \mathcal{S} \mathcal{A}_{t, 0}\left(X_{t}\right)$ decisions conditional on participating in the labor market $\left(\ell_{t}=0\right)$ depend only on $X_{t}$ and can be obtained from

$$
\left\{\mathcal{C}_{t, 0}\left(X_{t}\right), \mathcal{I}_{t, 0}\left(X_{t}\right), \mathcal{S} \mathcal{S} \mathcal{A}_{t, 0}\left(X_{t}\right)\right\} \equiv \underset{c_{t}, I_{t}, s a_{t}}{\operatorname{argmax}}\left\{\frac{c_{t}^{1-\eta_{c}}}{1-\eta_{c}}+\beta E\left[V_{t+1}\left(X_{t+1}, \gamma_{t+1}\right) \mid X_{t}, c_{t}, \ell_{t}=0, I_{t}, s s a_{t}\right]\right\}
$$

and the conditional value function is

$$
\widetilde{V}_{t, 0}\left(X_{t}\right) \equiv \frac{\left(\mathcal{C}_{t, 0}\left(X_{t}\right)\right)^{1-\eta_{c}}}{1-\eta_{c}}+\beta E\left[V_{t+1}\left(X_{t+1}, \gamma_{t+1}\right) \mid X_{t}, \mathcal{C}_{t, 0}\left(X_{t}\right), \ell_{t}=0, \mathcal{I}_{t, 0}\left(X_{t}\right), \mathcal{S S}_{\mathcal{A}_{t, 0}}\left(X_{t}\right)\right]
$$

Similarly, conditional on not working $\left(\ell_{t}=1\right)$, we can calculate the optimal consumption and claiming decision from

$$
\left\{\mathcal{C}_{t, 1}\left(X_{t}\right), \mathcal{S} \mathcal{S} \mathcal{A}_{t, 1}\left(X_{t}\right)\right\} \equiv \underset{c_{t}, s a_{t}}{\operatorname{argmax}}\left\{\frac{c_{t}^{1-\eta_{c}}}{1-\eta_{c}}+\beta E\left[V_{t+1}\left(X_{t+1}, \gamma_{t+1}\right) \mid X_{t}, c_{t}, \ell_{t}=1, I_{t}=0, s s a_{t}\right]\right\}
$$


and define the conditional value function apart from $\gamma_{t}$ to be

$$
\widetilde{V}_{t, 1}\left(X_{t}\right) \equiv \frac{\left(\mathcal{C}_{t, 1}\left(X_{t}\right)\right)^{1-\eta_{c}}}{1-\eta_{c}}+\beta E\left[V_{t+1}\left(X_{t+1}, \gamma_{t+1}\right) \mid X_{t}, \mathcal{C}_{t, 1}\left(X_{t}\right), \ell_{t}=1, I_{t}=0, \mathcal{S} \mathcal{S} \mathcal{A}_{t, 1}\left(X_{t}\right)\right] .
$$

Notice that since there is no serial correlation in the stochastic shocks of leisure, $\gamma_{t}$, the conditional policy and value functions defined in equations (8)-(11) do not depend on $\gamma_{t}$.

The individual works if

$$
\widetilde{V}_{t, 0}\left(X_{t}\right) \geq \widetilde{V}_{t, 1}\left(X_{t}\right)+\gamma_{t}
$$

This means that there exists a threshold value

$$
\gamma_{t}^{*}\left(X_{t}\right)=\widetilde{V}_{t, 0}\left(X_{t}\right)-\widetilde{V}_{t, 1}\left(X_{t}\right)
$$

such that

$$
\ell_{t}=\left\{\begin{array}{ll}
1, & \text { if } \gamma_{t} \geq \gamma_{t}^{*}\left(X_{t}\right) \\
0, & \text { if } \gamma_{t}<\gamma_{t}^{*}\left(X_{t}\right)
\end{array} .\right.
$$

We use the the parametric form for $\gamma_{t}$,

$$
\gamma_{t}=\exp \left(a_{0}+a_{\varepsilon} \varepsilon_{t}\right)
$$

where $\varepsilon_{t}$ follows an independent and identically-distributed standard normal distribution. Therefore $\gamma_{t}$ follows a log-normal distribution, $\ln \gamma_{t} \sim \mathcal{N}\left(a_{0}, a_{\varepsilon}^{2}\right)$. Then we can calculate the threshold value of $\varepsilon_{t}$ as ${ }^{5}$

$$
\varepsilon_{t}^{*}\left(X_{t}\right) \equiv \frac{1}{a_{\varepsilon}}\left\{\log \left(\gamma_{t}^{*}\left(X_{t}\right)\right)-a_{0}\right\} .
$$

Since $\gamma_{t}$ is log-normal,

$$
E\left(\gamma_{t} \mid \gamma_{t} \geq \gamma_{t}^{*}\left(X_{t}\right)\right)=\exp \left(a_{0}+\frac{a_{\varepsilon}^{2}}{2}\right) \frac{\Phi\left(a_{\varepsilon}-\varepsilon_{t}^{*}\left(X_{t}\right)\right)}{\Phi\left(-\varepsilon_{t}^{*}\left(X_{t}\right)\right)}
$$

Therefore

$$
\begin{aligned}
E\left[V_{t+1}\left(X_{t+1}, \gamma_{t+1}\right) \mid X_{t+1}\right]= & \Phi\left(\varepsilon_{t+1}^{*}\left(X_{t+1}\right)\right) \widetilde{V}_{t+1,0}\left(X_{t+1}\right)+\left(1-\Phi\left(\varepsilon_{t+1}^{*}\left(X_{t+1}\right)\right)\right) . \\
& {\left[\widetilde{V}_{t+1,1}\left(X_{t+1}\right)+\exp \left(a_{0}+\frac{a_{\varepsilon}^{2}}{2}\right) \frac{\Phi\left(a_{\varepsilon}-\varepsilon_{t+1}^{*}\left(X_{t+1}\right)\right)}{\Phi\left(-\varepsilon_{t+1}^{*}\left(X_{t+1}\right)\right)}\right] }
\end{aligned}
$$

${ }^{5}$ Note $\widetilde{V}_{t, 0}\left(X_{t}\right)>\widetilde{V}_{t, 1}\left(X_{t}\right)$ as long as $H_{t}>0$. 
Finally note that $X_{t+1}$ is a known function of $X_{t}, c_{t}, \ell_{t}, I_{t}, s s a_{t}$ and $\xi_{t}$, so to solve for

$$
E\left[V_{t+1}\left(X_{t+1}, \gamma_{t+1}\right) \mid X_{t}, c_{t}, \ell_{t}, I_{t}, s s a_{t}\right]=E\left[E\left(V_{t+1}\left(X_{t+1}, \gamma_{t+1}\right) \mid X_{t+1}\right) \mid X_{t}, c_{t}, \ell_{t}, I_{t}, s s a_{t}\right]
$$

we just need to integrate over the distribution of $\xi_{t}$. We assume it is i.i.d and follows a log-normal distribution,

$$
\log \left(\xi_{t}\right) \sim \mathcal{N}\left(-\frac{\log \left(\sigma_{\tilde{\zeta}}^{2}+1\right)}{2}, \log \left(\sigma_{\tilde{\zeta}}^{2}+1\right)\right)
$$

so that $\xi_{t}$ has mean of one and variance of $\sigma_{\xi}^{2}$.

\section{Estimation}

The estimation of the model is carried out using a two-step strategy. First, we preset parameters that either can be cleanly identified without explicitly using our model or are not the focus of this paper. In the second step, we estimate the remaining preference and production parameters of the model using Indirect Inference. The model is described by equations (1)-(7) and we summarize the parameters here. The parameters related to preferences are the intertemporal elasticity of consumption, $\eta_{c}$, the discount rate, $\beta$, the parameters determining the taste for leisure, $a_{0}$ and $a_{\varepsilon}$, and the bequest parameters $b_{1}$ and $b_{2}$. Human capital production is determined by $\delta, \pi, \alpha_{I}, \alpha_{H}$ and $\sigma_{\xi}$. Parameters related to the budget constraint are the interest rate $r$ and the consumption floor $\underline{c}$. Finally there are initial values for the state variables, assets, $A_{0}$, human capital, $H_{0}$, and Averaged Indexed Monthly Earnings, $A I M E_{0}$.

\subsection{Pre-set Parameters}

The set of parameters pre-set in the first stage includes the interest rate, initial wealth and initial AIME, the time discount rate, CRRA of utility in consumption, consumption floor, and bequest shifter. Specifically, we do not try to match moments in consumption or assets as those are not the focus of this paper. Given the total wealth level, the consumption allocation across periods are jointly determined by $\beta, \eta_{c}, A_{0}, \underline{c}, b_{1}$, and $b_{2}$. Separately identifying these parameters require matching moments related to consumption or asset

accumulation. For this reason we fix $\beta, \eta_{c}, A_{0}, \underline{c}$, and $b_{2}$, and only estimate $b_{1}$. of some of our results to these values. 
Table 1: Normalized or pre-set parameters

\begin{tabular}{lcc}
\hline Parameters & & Normalized/Pre-set Values \\
\hline Interest rate & $r$ & 0.03 \\
Discount & $\beta$ & 0.97 \\
Risk Aversion & $\eta_{c}$ & 4.0 \\
Initial wealth $^{a}$ & $A_{0}$ & 0.0 \\
Initial AIME $^{a}$ & $A I M E_{0}$ & 0.0 \\
Consumption floor $^{b}$ & $\underline{c}$ & 2.19 \\
Bequest shifter $^{c}$ & $b_{2}$ & 300.0 \\
\hline
\end{tabular}

${ }^{a}$ The initial age is 18 .

${ }^{b}$ The consumption floor is equivalent to $\$ 4380$ in $2004 \$$, since we normalize the total time endowment for labor supply at one period — which is 2000 hours-as one.

${ }^{c}$ The bequest shifter is equivalent to $\$ 600,000$.

One period is defined as one year. ${ }^{6}$ The initial period in our model corresponds to age 18 and ends at age $80 . .^{7}$ The early retirement age is 62 and the normal retirement age is 65. The risk free real interest rate is set as $r=0.03$ and the time discount rate is set as $\beta=0.97$. The coefficient of constant relative risk aversion (CRRA) in the utility from consumption is set as $\eta_{c}=4.0$. The consumption floor is set as $\underline{c}=2.19$, as estimated in French and Jones (2011). ${ }^{8}$

The parameter which determines the curvature of the bequest function is set as $b_{2}=$ $300 .{ }^{9}$ This number is close to French (2005) where he sets $b_{2}=250$ or French and Jones (2011) where they estimate $b_{2}=222 .{ }^{10}$ We assume all individuals start off their adult life with no wealth and zero level of AIME at age 18. These normalized or pre-set parameters are summarized in Table 1.

\subsection{Heterogeneity}

This leaves the following parameters: $b_{1}, a_{0}, a_{\varepsilon}, \delta, \pi, \alpha_{I}, \alpha_{H}, \sigma_{\xi}$ and $H_{0}$. We allow for heterogeneity in three of these: ability to learn $(\pi)$, ability to earn $\left(H_{0}\right)$, and tastes for leisure $\left(a_{0}\right)$. For computational reasons we only have nine types determining the joint distribution of $\left(a_{0}, \pi\right)$. Specifically, we model it as a nine-point Gauss-Hermite approximation of a joint normal distribution, which depends on five parameters: the mean and

\footnotetext{
${ }^{6}$ Mid-year retirement might be an issue. However, more than half of workers are never observed working half-time approaching retirement, so it would not be a big issue.

${ }^{7}$ The life expectancy for white males is 74.1 in 2000 and 76.5 in 2010.

${ }^{8} \underline{\mathrm{C}}=4380 / 2000=2.19$ since we normalize the total time endowment for labor supply at one period as one.

${ }^{9}$ It is equivalent to $\$ 600,000$ in 2004 U.S. dollar.

${ }^{10}$ They are $\$ 500,000$ and $\$ 444,000$ in their papers.
} 
variance of $a_{0}$, the mean and variance of $\pi$, and the correlation between the two. Respectively we write this as $\left(\mu_{a_{0}}, \sigma_{a_{0}}, \mu_{\pi}, \sigma_{\pi}, \rho\right)$. We emphasize that since we are only using nine points we are not assuming that the Gauss-Hermite is a good approximation of a normal, but rather view this as the parametrization itself. That is, we assume that the joint distribution of $\left(a_{0}, \pi\right)$ is a parametric discrete distribution with 9 points determined by the parameter vector $\left(\mu_{a_{0}}, \sigma_{a_{0}}, \mu_{\pi}, \sigma_{\pi}, \rho\right)$.

Since human capital is already a state variable in our model, we can be more flexible in modeling initial human capital. We allow it to be correlated with $\left(a_{0}, \pi\right)$ through the functional form

$$
H_{0}=\exp \left(\gamma_{0}+\gamma_{a_{0}} a_{0}+\gamma_{\pi} \pi+\sigma_{H_{0}} v\right)
$$

where $v \sim \mathcal{N}(0,1)$ is an i.i.d standard normal random variable.

\subsection{Estimation Procedure}

We apply Indirect Inference to estimate the parameters of interest, $\Theta$,

$$
\Theta=\{\underbrace{\mu_{a_{0}}, \sigma_{a_{0}}, a_{\varepsilon},}_{\text {leisure }} \underbrace{\delta, \alpha_{I}, \alpha_{H}, \sigma_{\tilde{\xi}}, \mu_{\pi}, \sigma_{\pi},}_{\text {human capital production }} \underbrace{b_{1},}_{\text {bequest }} \underbrace{\rho,}_{\left(a_{0}, \pi\right)} \underbrace{\gamma_{0}, \gamma_{a_{0}}, \gamma_{\pi}, \sigma_{H_{0}}}_{\text {correlation initial human capital }}\}
$$

according to the following procedure.

i) Calculate the auxiliary model from the data.

ii) Iterate on the following procedure for different values of $\Theta$ until the minimum distance has been found.

(a) Given a set of parameters, solve value functions and policy functions for the entire state space grid.

(b) Generate the life-cycle profile for each simulated individual.

(c) Calculate the auxiliary model from the simulation.

(d) Calculate the distance between the simulated auxiliary model and the data auxiliary model.

\subsection{Data and the Auxiliary Parameters}

Our primary data set is the Survey of Income and Program Participation (SIPP). The SIPP is comprised of a number of short panels of respondents and we use all of the panels starting with the 1984 panel and ending with the 2008 panel. To focus on as homogeneous a group as possible, the sample only includes white male high school graduates. 
Our measure of labor force participation is a dummy variable for whether the individual worked during the survey month. ${ }^{11}$ Clearly the aggregation is imperfect. We construct the hourly wage as the earnings in the survey month divided by the total number of hours worked in the survey month.

We begin estimation of the model from age 22 rather than 18 for two reasons. First, we have a short panel meaning that many 19 year old high school graduates may return to college after they leave the panel. Second, our model does not include any search or matching behavior, which might be important for the labor force patterns among very recent labor force entrance as they transition from school to work as suggested by literature (Topel and Ward, 1992; Neal, 1999). Our model does over-predict the labor supply for those individuals.

Four sets of moment conditions at each age from 22 to 65 are chosen to assemble the auxiliary model. We use a total of 230,657 panel observations from 80,519 different respondents.

i) The labor force participation rates (LFPR);

ii) The first moments of the logarithm of observed wages;

iii) The first moments of the logarithm of observed wages after controlling for individual fixed effects. ${ }^{12}$

iv) The second moments (standard deviation) of the logarithm of observed wages.

As is standard in the literature on estimation of Ben-Porath style human capital we assume that wages in the data correspond to

$$
W_{t}=H_{t}\left(1-I_{t}\right)
$$

in the model. We match both age-wage profiles, with and without controlling for individual fixed effect as the two have quite different patterns.

Figures 1a-1c present these four profiles. Figure 1a plots the labor force participation rates between age 22 and 65 . Figure $1 \mathrm{~b}$ plots two log wage profiles. The first one is the $\log$ wage profile from the pooled sample, while the second one is the log wage profile after

\footnotetext{
${ }^{11}$ In SIPP an individual is observed in at most three months each year. If an individual is observed working more than $50 \%$ of the time then he is categorized as participating in the labor force, otherwise not. If one is sampled twice for the year and is observed working in one month only, the participation status is determined randomly ( $50 \%$ for each possibility).

${ }^{12}$ To construct these moments we first regress log wage on the age dummies and survey year dummies and obtain the predicted log wage, denoted as $z$. We pick a base age (age 30) and calculate the average predicted log wage at the base age for each year, denoted as $\bar{z}_{a, j}$, where $a$ is the base age and $j$ is for survey year. We then pick a base year $y$ and calculate the difference of $\bar{z}_{a, j}$ between each year $j$ and the base year $y$, denoted as $\Delta \bar{z}_{a, j}$. Finally we calculate the difference between the original log wage and $\Delta \bar{z}_{a, j}$ and define the result as $\ln \tilde{W}_{t}$, which is the $\log$ wage after filtering out the time fixed effects.
} 
controlling for individual fixed effects. The original log wage profile has a hump shape, but the one filtering out individual fixed effects does not decline within the examined period which is between age 22 and 65 . Figure $1 \mathrm{c}$ shows the extent to which the variance of $\log$ wages increases with age.

The most interesting result in Figures 1a-1c is the discrepancy between the age-wage profiles with or without controlling for individual fixed effects. This has been documented in various data sets, including the National Longitudinal Survey of Older Men (NLSOM) data (Johnson and Neumark, 1996), the Panel Study of Income Dynamics (PSID) data (Rupert and Zanella, 2012), and the Health and Retirement Survey (HRS) data (Casanova, 2013). These papers find that after controlling for individual fixed effects the age-wage profile is flatter than the hump-shaped age-wage profile estimated using pooling observations, and it does not decline until 60s or late 60s. All of these papers argue that this evidence is not consistent with the traditional human capital model since the traditional human capital model would predict a hump-shaped wage. The intuition is that when the human capital depreciation outweighs the investment, wages start to decline which generates a hump-shaped profile. Fitting the wage profile after controlling for fixed effects makes our problem more challenging because we need to explain the decrease in labor supply later in life when there is little evidence that wages decline.

To further verify this result we compare our SIPP results with the Current Population Survey (CPS) data. From the CPS Merged Outgoing Rotation Groups (MORG) data, we match the same respondent in two consecutive surveys using the method proposed in Madrian and Lefgren (2000), and we have a short panel with each individual interviewed twice, one year apart. ${ }^{13}$ We construct a similar short panel from the CPS March Annual Social and Economic Supplement files (March). The difference is that the wage information is collected from the reference week in the CPS MORG data and from the previous year in the CPS March data.

Figure 2 presents the age-wage profiles with or without controlling for individual fixed effects for male high school graduates from the 1979-2012 CPS MORG data and the 1979-2007 CPS March data. We find a somewhat even larger discrepancy in the age-wage profiles as in the SIPP data presented in Figure $1 b .^{14}$

\footnotetext{
${ }^{13}$ For MORG data, they are the fourth and eighth interview.

${ }^{14}$ Time fixed effects are filtered out, as described in footnote 12. We use the same starting year for the CPS MORG data and the CPS March data. Using the 1979-2007 CPS MORG data generates essentially same profiles.
} 
Table 2: Estimates in the baseline model ${ }^{a}$

\begin{tabular}{|c|c|c|c|}
\hline Parameters & & Estimates & Standard Errors \\
\hline Leisure: Standard Deviation of Shock & $a_{\varepsilon}$ & 0.433 & $(0.012)$ \\
\hline Human Capital Depreciation & $\delta$ & 0.101 & $(0.007)$ \\
\hline Human Capital Production Function: I factor & $\alpha_{I}$ & 0.076 & $(0.019)$ \\
\hline Human Capital Production Function: $H$ factor & $\alpha_{H}$ & 0.151 & $(0.021)$ \\
\hline Standard Deviation of Human Capital Innovation & $\sigma_{\xi}$ & 0.405 & $(0.082)$ \\
\hline Bequest Weight & $b_{1}$ & 424,070 & $(90,735)$ \\
\hline Parameter heterogeneity $^{b}$ & & & \\
\hline Leisure: Mean of Intercept & $\mu_{a_{0}}$ & -6.525 & $(0.050)$ \\
\hline Leisure: Standard Deviation of Intercept & $\sigma_{a_{0}}$ & 0.874 & $(0.053)$ \\
\hline Human Capital Productivity, Mean & $\mu_{\pi}$ & 1.758 & $(0.069)$ \\
\hline Human Capital Productivity, Standard Deviation & $\sigma_{\pi}$ & 0.583 & $(0.026)$ \\
\hline Correlation between $a_{0}$ and $\pi$ & $\rho$ & -0.893 & $(0.064)$ \\
\hline Initial Human Capital Level at Age 18 & & & \\
\hline Intercept & $\gamma_{0}$ & 1.625 & $(0.099)$ \\
\hline Coefficient on $a_{0}$ & $\gamma_{a_{0}}$ & 0.052 & $(0.007)$ \\
\hline Coefficient on $\pi$ & $\gamma_{\pi}$ & 0.531 & $(0.060)$ \\
\hline Standard Deviation of Error Term & $\sigma_{H_{0}}$ & 0.239 & $(0.036)$ \\
\hline$\chi^{2}$ Statistic $=212^{c}$ & \multicolumn{3}{|c|}{ Degrees of freedom $=161$} \\
\hline
\end{tabular}

${ }^{a}$ Indirect Inference estimates. Estimates use a diagonal weighting matrix. Standard errors are given in parentheses.

${ }^{b}$ The joint distribution of $\left(a_{0}, \pi\right)$ is a parametric discrete distribution with nine points determined by these five parameters, using a nine-point Gauss-Hermite approximation. ${ }^{c}$ This is the J-statistic. The critical values of the $\chi^{2}$ distribution are $\chi_{(161,0.01)}^{2}=206$, $\chi_{(161,0.005)}^{2}=212, \chi_{(161,0.001)}^{2}=222$.

\section{Estimation Results}

The estimates of the parameters are listed in Table 2. Of particular importance are the depreciation rate, $\delta$, curvature in the human capital production function, $\alpha_{I}$, and $a_{\varepsilon}$ which determines the elasticity of labor supply. Before discussing these parameter values we examine the fit of the model in Figures 3a-3d. ${ }^{15}$

The first and central point is that our parsimonious model can reconcile the main facts in the data: a small increase in labor supply/large increase in wages at the beginning of the life-cycle along with the large decrease in labor supply/small decrease in wages at the

\footnotetext{
${ }^{15}$ The overidentification test statistic is reported in the bottom of Table 2 . The model is rejected at the $1 \%$ level but not at the $0.5 \%$ level. The fact that we reject is not surprising given the simplicity of our model and the size of our sample. One could easily add some extra parameters to pass the statistical criterion, but this is not our goal. Our goal is to use a simple model that does a very good job of capturing the life-cycle patterns.
} 
end of the life-cycle. ${ }^{16}$

The simulated labor force participation rate increases slightly between age 22 and 30 as shown in Figure 3a.

Our main result is that this simple model is able to generate a massive decline in labor supply between age 55 and 65, which fits the sharp decline of labor force participation rates within that age period in the data and simultaneously the flat wage profile in the fixed effect model.

Our model generates similar discrepancy between the log wages with and without controlling for individual fixed effects, as shown in Figures $3 b$ and $3 c$, and both profiles fit the data well. Log wages after filtering out individual fixed effects increase at a decreasing pace from age 22 to age 55 and then decreases slightly (Figure 3b). On the other hand, Figure $3 c$ shows that the original log wage profile presents a hump shape which almost replicates the data profile.

The model also replicates the log wage variation as in the data (Figure 3d). This increasing variation mainly comes from the heterogeneity in the parameters. Without heterogeneity in parameters, the wage variation would decrease with age as human capital would converge due to concavity of the production function. With heterogeneity, the human capital level might diverge, depending on parameter values.

We obtain our fit of the life-cycle profiles of labor supply and log wages despite the lack of any explicit time-dependent preference, production or constraints in our model. Two key features of our model make them possible: the human capital depreciation and the separation between the effective labor and observed labor. We discuss each of these in turn.

We argued above that human capital depreciation is essential for matching the labor force participation profile. This discussion implies that our estimate of a depreciation value $\delta=0.101$ plays a major role explaining the pattern of wages and life cycle labor supply. Given this, it is important to place this value into the range of estimates in the literature. This is not easily done as there is a very large range of estimates-some larger than our $10.1 \%$ estimate and some smaller. There are broadly three different literatures that estimate related parameters. The first of these is motivated by family leave for women and tries to estimate the effect of career interruption on wages. It finds estimates ranging from $1.5 \%$ per year to $25 \% .{ }^{17}$ A second literature looks at displacement

\footnotetext{
${ }^{16}$ One should keep in mind that our parsimonious specification might be a limitation on our policy counterfactuals as other features that we have not explicitly modeled might impact those simulations.

${ }^{17}$ A classic early paper on this topic is Mincer and Polachek (1974) which estimates a net depreciation rate of around 1.5 percent per year. Mincer and Ofek (1982) go beyond this to discuss the difference between short term and long term losses from interruption. In the long run individuals invest in human capital to
} 
from the Displaced Worker Survey and also finds a wide range of estimates-many of which are not directly comparable to ours. ${ }^{18}$ A third literature examines the effect of the length of an unemployment spell on the wage at rehire. Schmieder et al. (2014) is a recent and convincingly identified paper of this type. They estimate the effect using a regression discontinuity with German data. In Germany the length of eligibility for unemployment insurance depends on age with jumps at ages 42 and at 44 . They see an increase in unemployment duration at these two discontinuity points, so they use the kink points as instruments in order to estimate the effect of the length of unemployment duration on reemployment wages. They find that one extra month of unemployment leads to a decrease in wages of $0.8 \%$ which gives an annual rate remarkably close to our estimate of $10.1 \%$. While it looks at women in England, Blundell et al. (2015) is of similar style to our paper in the sense that it is a structural life-cycle model of labor supply and human capital formation. Interestingly, their analysis reveals a substantial depreciation of human capital ranging from $6 \%$ to $11 \%$.

A second important feature for explaining the life-cycle profiles comes from a point emphasized by Heckman et al. (1998a): observed wages are different than observed human capital. We see in figure $3 \mathrm{~b}$ that in both the model and the data, once fixed effects are accounted for, wages are close to flat for ages 50-65 despite the fact that there is a large decrease in labor supply. This distinction between human capital and wages can help explain this effect. As shown in Figure 4a, at older ages (around 60) the actual human capital level has already depreciated to a relatively low level, even though the observed wage level is still quite high. This is due to the quick decline in investment that happens around that time. This means that measured wages, $H_{t}\left(1-I_{t}\right)$, can be flat while $H_{t}$ is decreasing as long as $I_{t}$ is decreasing as well. The time investment profile in Figure $4 \mathrm{~b}$

offset the initial loss, so Mincer and Ofek (1982)'s definition of short term losses is more closely related to our concept of depreciation. Using panel data methods for the National Longitudinal Survey of Mature Women they find estimates ranging from 5.6\% to $8.9 \%$. Light and Ureta (1995) use National Longitudinal Survey of Youth 1979 data and estimate that the immediate effect of a year of non-participation in the labor market leads to a decline in earnings of 25\%. Kunze (2002) and Gorlich and de Grip (2009) both use German data (IAB employment sample and German Socio-economic panel respectively). Kunze (2002) finds estimates of about 2-5\% wages losses for women from unemployment spells but about 13-18\% from parental leave. Gorlich and de Grip (2009) find a variety of results ranging from around 1.5\% to 5\% depending on the type of spell.

${ }^{18}$ While much of this literature is more focused on earnings than wages, some papers look at weekly earnings. Both Farber (1993) and Ruhm (1991) estimate the effect of a displacement on re-employment wages and obtain a range of estimates with most being around declines of $10 \%$ but varying from $6.5 \%$ to $16.9 \%$. These numbers are not annualized but are just from the incidence of displacement. Li (2013) uses the same data but produces annualized versions so that the effects can be more easily compared to our estimate of $\delta$. She estimates the effects for many different occupations with a huge range of estimates across occupations. Focusing on the three largest occupations she finds a deprecation of $9.4 \%$ for Installation and Repair workers, $7.7 \%$ for Production workers, and 17.4\% for workers in Transportation. 
matches this implication. The solid line is the unconditional investment profile while the dashed line is the average investment profile conditional on working. These two profiles are very close to each other at prime ages, and both decrease over time.

The relatively high value of investment late in the working career is also related to why we find a much smaller level of the human capital curvature parameter, $\alpha_{I}$, compared to the literature summarized in Browning et al. (1999). The larger is $\alpha_{I}$ the steeper is the decline in human capital investment with age. At the extreme when $\alpha_{I}=1$ one gets a "bang-bang" solution with full investment to a point and then zero investment thereafter. Because depreciation is large, in order to fit the relatively flat wage profile that we see at older ages one needs a lot of investment at this age which requires a small value of $\alpha_{I}$. Heckman et al. (1998a) fit the wage data with a much larger value of $\alpha_{I}$ but our models are quite different in a number of ways including the fact that this model includes leisure and in their model they set deprecation to zero.

At the early stage of the life-cycle, workers invest a considerable amount of time in human capital production which drives up both the human capital level and the wage. Once the worker reaches his mid-career (around age 45), he reduces the time investment at an increasing rate and human capital starts to decrease. As the worker spends less of his working time investing, wages continue to increase. One can see in Figure 4a that the observed wage keeps increasing after age 45 and peaks around 52, after which the observed wage starts declining slowly. After age 62, however, since the worker has already allocated most of his time in effective working, there is no further room for such adjustment. As a result, the observed wage declines at almost the same rate at which human capital depreciates. This leads to large falls in labor supply at older ages.

Such separation also helps generate the pattern that the working hours profile peaks earlier than the wage profile (Weiss, 1986). Working hours increase slightly with age when the worker is young, with a large portion devoted to human capital investment. The working hours profile peaks around age 40 and starts declining. However, with proportionally less time devoted to human capital investment and more time to effective labor supply (Figure $4 b$ ), the observed wage increases from labor market entry to about age 52 .

\subsection{The Role of Health}

We have intentionally kept our model simple to show that human capital can explain the dramatic fall in labor supply at the end of the life-cycle. However, there are many alternative reasons why labor supply might decline. Aside from Social Security 
rules, which we have already incorporated, the most important is health (e.g. Currie and Madrian 1999, French and Jones 2011). If the primary reason for retirement is health, its omission might seriously distort our results. In this subsection we incorporate health into our model in a very flexible way. We show that while it is an important factor, it is not the primary driver of retirement.

We allow for an additional state variable-health status, $S_{t} \in\{0,1\}$, with 0 being in good health and 1 in bad health. Each individual is assumed to have good health at the beginning of the first period, $S_{0}=0$. The health status evolves exogenously according to a time-dependent probability transition matrix, and is realized at the beginning of each period before any choice is made. ${ }^{19}$

We allow the taste for leisure in the utility function (1) to depend on the health status and change with age,

$$
\gamma_{t}=\exp \left(a_{0}+S_{t}\left(a_{s 0}+a_{s t} t\right)+a_{\varepsilon} \varepsilon_{t}\right) .
$$

That is, individuals with bad health have a different taste for leisure than those with good health and this difference changes as they age. ${ }^{20}$ We refer to this model as the baseline health model.

To estimate these two new parameters, $a_{s 0}$ and $a_{s t}$, we include the difference in labor force participation rates between workers with good health and workers with bad health, from age 30 to 65 into our moment conditions. The data moments are derived from the 1963-2007 CPS March data.

We then re-estimate the whole model. The fit of the model is presented in Figure 5a. Including health (and the additional moments shown in panel (ii) of Figure 5a) into the model does not improve its performance on the original moments in any significant way.

However, just because the fit does not improve much does not imply that health does not play an important role. It may just be that either health or human capital could explain retirement. ${ }^{21}$ To explore the implications of health we use the model estimated with health, but then simulate a counterfactual in which there was no health change. Specifically, we eliminate the importance of health for individuals over 50 in two different ways-we do not allow their health to worsen and we eliminate the interaction between health and preferences for work. Specifically, we simulate an experiment in which the

\footnotetext{
${ }^{19}$ The health transition matrix is estimated from the Panel Study of Income Dynamics (PSID) data.

${ }^{20} \mathrm{~A}$ key aspect of the thought experiment behind this paper is to not allow preferences to vary systematically with age in our baseline model. In practice we can only fit the interaction of health and labor supply in the data by allowing for an interaction between health and tastes for leisure. The main point of this subsection is that health is not essential to explain the profiles, so even though we are favoring the model with health by allowing this extra flexibility, health has a relatively minor role.

${ }^{21}$ Note that this is not to say they are not separately identified. The extra moments we use for the health model identify the importance of health.
} 
health status that an individual had at age 50 remains for the rest of their life. Secondly, in addition to fixing the health status at age 50, for individuals with bad health status on and after age 50, we assume their taste for leisure does not increase with age. That is, letting $t^{*}$ be the time period in which the individual turns 50 , we assume that the taste for leisure is now

$$
\gamma_{t}=\exp \left(a_{0}+S_{t}\left(a_{s 0}+a_{s t} \cdot \min \left\{t, t^{*}\right\}\right)+a_{\varepsilon} \varepsilon_{t}\right)
$$

and $S_{t}=S_{50}$ for $t>t *$. We then re-solve the modified model and simulate the life-cycle profile for each individual using the same estimates from the aforementioned baseline health model. ${ }^{22}$ The profiles of labor supply and human capital from the second experiment are plotted in Figure 5b. The difference between the counterfactual and the baseline health model is very small in both the labor force participation rate and the human capital level. This implies that at least in our model health is not a major factor driving retirement. This result confirms findings in the previous literature. French (2005) estimates that the changes in health attribute to roughly $10 \%$ of the drop in the labor force participation rates between ages 55 and 70, and the contribution to hours worked by workers near retirement is much smaller. Blau and Shvydko (2011) also report that health deterioration is an important but not major cause of retirement.

\section{Changes in Tax and Social Security}

The preceding sections show that the model fits the life-cycle profiles of labor supply and log wages in the data well. In this section, we use the model to predict how changes in the taxes or Social Security rules would affect behavior in labor supply, human capital investment and the resulting log wage profile. We conduct seven counterfactual policy experiments which reflect various changes in the tax codes and Social Security rules. The results of these experiments are summarized in columns 2-8 of Panel A in Table 3, where the first column is the baseline model. All numbers are summations throughout the lifecycle (from age 18 to 80 ).

\subsection{The Baseline Model}

The first experiment increases the income tax proportionally by $50 \%$. Column 2 shows that after the tax increase, an average individual works additional 1.25 years over the life-

\footnotetext{
${ }^{22}$ We are assuming that agents have rational expectations and are aware that their health status will not change. We have also simulated models in which they are not aware that their health status will remain fixed-it does not change the basic message.
} 
Table 3: Effects of changing taxes or Social Security rules

\begin{tabular}{|c|c|c|c|c|c|c|c|c|c|c|c|c|c|c|c|}
\hline & \multirow{2}{*}{$\begin{array}{c}1 \\
\frac{\text { Baseline }^{\prime}}{\text { Level }^{a}}\end{array}$} & \multicolumn{2}{|c|}{$\begin{array}{c}2 \\
\text { Tax Increase } 50 \% \\
\end{array}$} & \multicolumn{2}{|c|}{$\begin{array}{c}3 \\
\text { No Earnings Test } \\
\end{array}$} & \multicolumn{2}{|c|}{$\begin{array}{c}4 \\
\text { NRA }=67 \\
\end{array}$} & \multicolumn{2}{|c|}{$\begin{array}{c}5 \\
\text { Reduce SSB 20\% } \\
\end{array}$} & \multicolumn{2}{|c|}{$\begin{array}{c}6 \\
\text { No SS Taxes } \\
\end{array}$} & \multicolumn{2}{|c|}{$\begin{array}{c}7 \\
\text { No SS Benefit } \\
\end{array}$} & \multicolumn{2}{|c|}{$\begin{array}{c}8 \\
\text { No SS System } \\
\end{array}$} \\
\hline & & $\overline{\Delta \text { Level }^{b}}$ & $\% \Delta^{c}$ & $\overline{\Delta \text { Level }}$ & $\% \Delta$ & $\Delta \overline{\text { Level }}$ & $\% \Delta$ & $\overline{\Delta \text { Level }}$ & $\% \Delta$ & $\Delta \overline{\text { Level }}$ & $\% \Delta$ & $\overline{\Delta \text { Level }}$ & $\% \Delta$ & $\overline{\Delta \text { Level }}$ & $\% \Delta$ \\
\hline \multicolumn{16}{|c|}{ Panel A: Baseline Model } \\
\hline LFPR & 40.356 & 1.249 & 3.096 & 0.387 & 0.959 & 0.409 & 1.012 & 0.633 & 1.570 & -1.947 & -4.826 & 5.220 & 12.934 & 2.647 & 6.560 \\
\hline Effective Labor & 37.997 & 1.187 & 3.125 & 0.364 & 0.957 & 0.382 & 1.006 & 0.594 & 1.563 & -1.820 & -4.790 & 4.911 & 12.926 & 2.502 & 6.585 \\
\hline Pre-tax Income & 637.759 & 28.831 & 4.521 & 5.842 & 0.916 & 8.484 & 1.330 & 13.805 & 2.165 & -45.555 & -7.143 & 97.452 & 15.280 & 37.153 & 5.826 \\
\hline Average $\ln w$ & 2.613 & 0.012 & 0.468 & 0.008 & 0.322 & 0.007 & 0.268 & 0.015 & 0.569 & -0.020 & -0.777 & 0.050 & 1.903 & 0.021 & 0.792 \\
\hline Human Capital & 917.382 & 25.901 & 2.823 & 6.465 & 0.705 & 7.665 & 0.836 & 12.160 & 1.326 & -39.947 & -4.354 & 82.071 & 8.946 & 33.769 & 3.681 \\
\hline Investment & 2.359 & 0.062 & 2.631 & 0.023 & 0.988 & 0.026 & 1.122 & 0.040 & 1.684 & -0.127 & -5.395 & 0.308 & 13.059 & 0.145 & 6.147 \\
\hline \multicolumn{16}{|c|}{ Panel B: Exogenous Model } \\
\hline LFPR & 40.412 & 1.524 & 3.771 & 0.084 & 0.208 & 0.338 & 0.835 & 0.530 & 1.311 & -2.213 & -5.475 & 3.456 & 8.552 & 0.907 & 2.245 \\
\hline Effective Labor & 40.412 & 1.524 & 3.771 & 0.084 & 0.208 & 0.338 & 0.835 & 0.530 & 1.311 & -2.213 & -5.475 & 3.456 & 8.552 & 0.907 & 2.245 \\
\hline Pre-tax Income & 655.258 & 25.849 & 3.945 & 1.794 & 0.274 & 5.235 & 0.799 & 8.285 & 1.264 & -33.535 & -5.118 & 50.490 & 7.705 & 13.300 & 2.030 \\
\hline Average $\ln w$ & 2.625 & 0.006 & 0.248 & 0.000 & 0.015 & 0.001 & 0.024 & 0.002 & 0.076 & -0.003 & -0.103 & 0.000 & -0.009 & -0.002 & -0.069 \\
\hline \multicolumn{16}{|c|}{ Panel C: Learning-by-doing Model } \\
\hline LFPR & 40.232 & 1.287 & 3.198 & 0.257 & 0.638 & 0.821 & 2.040 & 1.186 & 2.948 & -3.474 & -8.635 & 6.368 & 15.827 & 3.482 & 8.655 \\
\hline Effective Labor & 40.232 & 1.287 & 3.198 & 0.257 & 0.638 & 0.821 & 2.040 & 1.186 & 2.948 & -3.474 & -8.635 & 6.368 & 15.827 & 3.482 & 8.655 \\
\hline Labor Income & 629.286 & 28.301 & 4.497 & 3.825 & 0.608 & 13.293 & 2.112 & 19.829 & 3.151 & -60.550 & -9.622 & 112.483 & 17.875 & 49.189 & 7.817 \\
\hline Average $\ln w$ & 2.572 & 0.028 & 1.075 & 0.014 & 0.551 & 0.016 & 0.620 & 0.026 & 1.013 & -0.181 & -7.026 & 0.093 & 3.602 & 0.064 & 2.489 \\
\hline Human Capital & 844.058 & 23.218 & 2.751 & 4.107 & 0.487 & 12.131 & 1.437 & 16.924 & 2.005 & -48.275 & -5.719 & 84.723 & 10.038 & 41.654 & 4.935 \\
\hline \multicolumn{16}{|c|}{ Panel D: Model with Health } \\
\hline LFPR & 41.926 & 1.065 & 2.541 & 0.191 & 0.456 & 0.379 & 0.904 & 0.607 & 1.448 & -1.727 & -4.118 & 4.275 & 10.198 & 2.162 & 5.156 \\
\hline Effective Labor & 39.625 & 1.026 & 2.589 & 0.180 & 0.454 & 0.355 & 0.897 & 0.571 & 1.440 & -1.621 & -4.090 & 4.046 & 10.212 & 2.060 & 5.199 \\
\hline Pre-tax Income & 653.149 & 25.507 & 3.905 & 3.179 & 0.487 & 7.924 & 1.213 & 12.872 & 1.971 & -41.183 & -6.305 & 81.956 & 12.548 & 30.333 & 4.644 \\
\hline Average lnw & 2.603 & 0.014 & 0.531 & 0.004 & 0.143 & 0.006 & 0.215 & 0.009 & 0.348 & -0.023 & -0.867 & 0.034 & 1.296 & 0.006 & 0.213 \\
\hline Human Capital & 914.487 & 22.221 & 2.430 & 3.606 & 0.394 & 7.127 & 0.779 & 11.218 & 1.227 & -34.736 & -3.798 & 67.618 & 7.394 & 27.030 & 2.956 \\
\hline Investment & 2.301 & 0.039 & 1.715 & 0.011 & 0.487 & 0.024 & 1.031 & 0.036 & 1.581 & -0.106 & -4.599 & 0.229 & 9.958 & 0.101 & 4.408 \\
\hline
\end{tabular}

${ }^{a}$ The "Level" column refers to the total value aggregated over the whole life-cycle, except the "Average lnw" which is the average yearly log wages. For example, in the baseline model, the total LFPR is 40.356 years from 18 to 80 .

${ }^{b}$ The "$\Delta$ Level" column refers to the difference of the total value between the current experiment and the baseline model. For example, in the "No Earnings Test" case, the LFPR is 0.387 years higher than that in the baseline model across the whole life-cycle from 18 to 80 .

${ }^{c}$ The "\% $\Delta$ " column refers to the percentage of the difference in the " $\Delta$ Level" column relative to the level in the baseline model. For example, in the "No Earnings Test" case, the LFPR increases by 0.387 years which is equivalent to $0.959 \%$ of the LFPR in the baseline model. 
cycle, equivalent to $3.1 \%$ of the total labor supply. Most of the increase in the labor supply is allocated to the effective labor, which increases by 1.19 years. The investment also increases by 0.06 years or $2.6 \%$, which leads to $2.8 \%$ increase in the human capital level and $0.47 \%$ increase in the observed log wages. ${ }^{23}$ A tax hike has both substitution and income effects. The substitution effect discourages labor supply while the income effect encourages labor supply. Our first experiment indicates that in our model the income effect dominates the substitution effect and this is the case with most of our experiments. ${ }^{24}$ We also see that human capital investment increases in this experiment. The direct effect of taxes discourages human capital investment, but the increase in labor supply (and in particular delayed retirement) increases human capital investment.

The manner in which Social Security rules affect labor supply and wages is of central interest to policy makers. The six experiments in columns 3-8 are devoted to answering these questions. In the first three we manipulate the current Social Security rules (columns 3-5) while in the last three we decompose the distortionary effects of the current Social Security system (columns 6-8).

First we remove the Social Security earnings test, which is effective between age 62 and 70 in the baseline model. In the second one, we delay Normal Retirement Age (NRA) by two years: the new NRA is age 67 in this counterfactual experiment while it is age 65 in the baseline model ${ }^{25}$. In the third one, we reduce the Social Security benefit proportionally by $20 \%$. The results are presented in columns $3-5$ in Table 3 . Removing the Social Security earnings test between ages 62 and 70 has a smaller effect on all variables; delaying the normal retirement age by two years, has a slightly larger impact; reducing the generosity of the social security benefit has the largest effect among these three. ${ }^{26}$ For instance, they increase the labor force participation by four-and-a-half, five, or seven-and-a-half months, respectively. One important feature is that the change in the labor supply does not only happen later in the life-cycle when the policy change is directly effective, it takes place over the whole life-cycle, as indicated in Figure 6a. When the NRA is delayed two years or the Social Security benefit is reduced, workers also invest more and therefore have higher

\footnotetext{
${ }^{23}$ Other papers have looked at the effects of taxes and human capital with this type of model. Examples are Heckman et al. (1998b), Heckman et al. (1999), and Taber (2002). These experiments are quite different as labor supply makes a large difference here so the results are not directly comparable.

${ }^{24}$ We also experimented by simulating with a lower coefficient of risk aversion of $\eta_{c}=2$ rather than 4 . In this case the income effect still is larger than the substitution effect, but it is closer. For example in the $50 \%$ tax increase labor supply increases by $0.7 \%$ rather than $3.1 \%$.

${ }^{25}$ Technically speaking, the NRA depends on the birth year. But this does not affect our results since for the majority of retirees in our data, the NRA is 65.

${ }^{26}$ The benefit withdrawn by the earnings test is paid back later in the form of Delayed Retirement Credit (DRC). Therefore the net effect of Social Security earnings test is not clear and depends on the life expectancy which affects the actuarial fairness.
} 
human capital levels, which leads to higher wages at old ages (Figure 6a). The wage difference is negligible before age 60 but increases substantially after that, reaching $3 \%$ or $5 \%$ around age 67 . Ignoring such a wage response in experiments involving retirement policy will most likely introduce bias.

In the last three experiments, we decompose the effect of the current U.S. Social Security system into the individual effects of the Social Security taxes and the Social Security benefit. In Column 6 we keep the Social Security benefit but eliminate the Social Security taxes (the payroll taxes); ${ }^{27}$ in Column 7 we remove the Social Security benefit completely but keep the Social Security taxes; in Column 8 we remove the entire Social Security system, that is, both the Social Security taxes and the benefit. Removing the Social Security taxes induces an average individual to supply 1.95 years less labor. This is not surprising because removing the Social Security taxes is essentially a universal cut in the tax rate. In our tax hike counterfactual, the income effect dominates the substitution effect as is true for the cut in social security taxes as well. Analogously, removing the Social Security benefit induces more labor supply. However, the increase in the labor supply is 5.22 years, which is much higher than 1.95 years reduction of labor supply in the case of removing Social Security Taxes. The combination of these two effects leads to the results in the last experiment where both the Social Security taxes and benefit are removed. Column 8 indicates that eliminating the current Social Security system increases average labor supply by 2.65 years over the life-cycle. Such observation is also mentioned qualitatively in Gustman and Steinmeier (1986) and Rust and Phelan (1997). Figure 6b shows that the increases in the labor supply and log wages are most phenomenal at old ages in the experiment without Social Security system.

Another point worth emphasizing is that in almost every policy counterfactual, the increase in the endogenously determined wage levels are substantial. This is especially true at old ages: $6 \%$ when removing the earnings test or reducing Social Security benefit, $3 \%$ when delaying NRA by two years, and over $10 \%$ when removing Social Security benefit or the entire system. ${ }^{28}$ These are caused by increases in the human capital levels as a result of higher investment. For this reason, it is likely that ignoring the human capital investment channel would generate bias in terms of predicting LFPR at old ages in similar experiments.

\footnotetext{
${ }^{27}$ The income taxes are still effective.

${ }^{28}$ The only exception is the experiment of removing Social Security taxes.
} 


\section{Conclusion}

This paper develops and estimates a rich life-cycle model that merges a Ben-Porath style human capital framework with a neoclassical style framework with endogenous labor supply and retirement framework. In the model, each individual makes decisions on consumption, human capital investment, labor supply and retirement. Investment in human capital generates wage growth over the life-cycle, while depreciation of human capital is the main force generating retirement. We show that the parsimonious model is able to fit the main features of life-cycle labor supply, wages (with and without fixed effects) as well as retirement. In particular we can fit both the large increase in wages and small changes in labor supply at the beginning of the life-cycle along with the small changes in wages but large changes in labor supply at the end. We incorporate health into the model and show that while this is an important factor, human capital remains the main explanation for the decline in labor supply for older workers.

We use the estimated model to simulate the impacts of various policy changes. While prior work typically takes the wage process as given and focuses on the retirement decision, we are able to model the effect of the policy change on the wage process and the labor supply decisions. As we show in our model, less generous Social Security benefits result in higher labor supply later in the life-cycle, so workers adjust their investment over the life-cycle. This results in a higher human capital level as well as higher labor supply earlier in the life-cycle. Compared with the baseline model, the labor supply response to policy changes are much smaller in most experiments when human capital is completely exogenous, but slightly larger in most experiments in the learning-by-doing model. The bottom line is that modeling labor supply and human capital decisions jointly is critical in an analysis of the effects of policy changes. While presumably other factors would be important for explaining other features of labor markets, endogenous labor supply is crit-

ical for understanding life-cycle human capital investment and life-cycle human capital investment is critical for understanding life-cycle labor supply. 
Figure 1a: Labor force participation rate-SIPP data

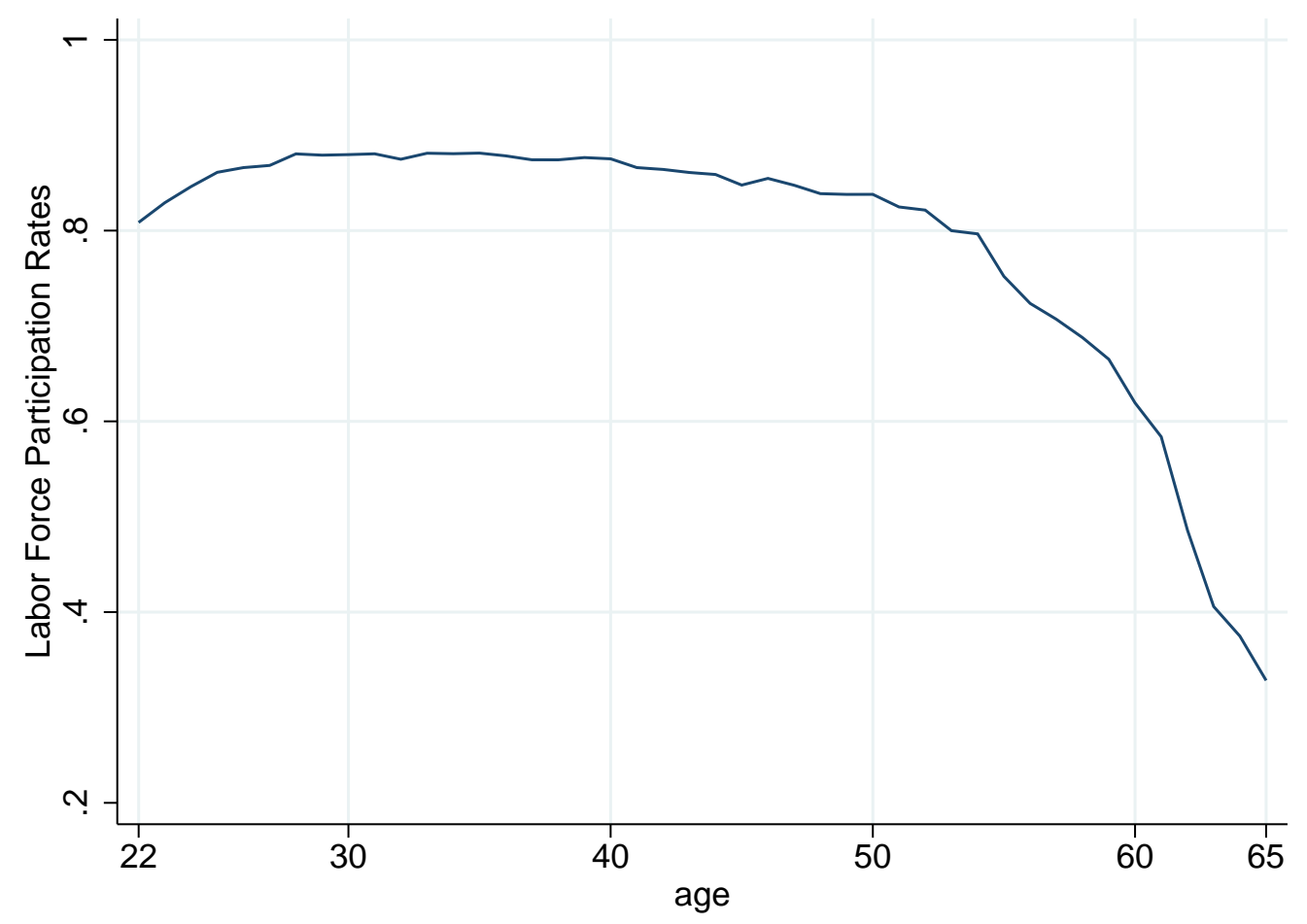

Figure 1b: Log wages with and without controlling for individual fixed effects—SIPP data

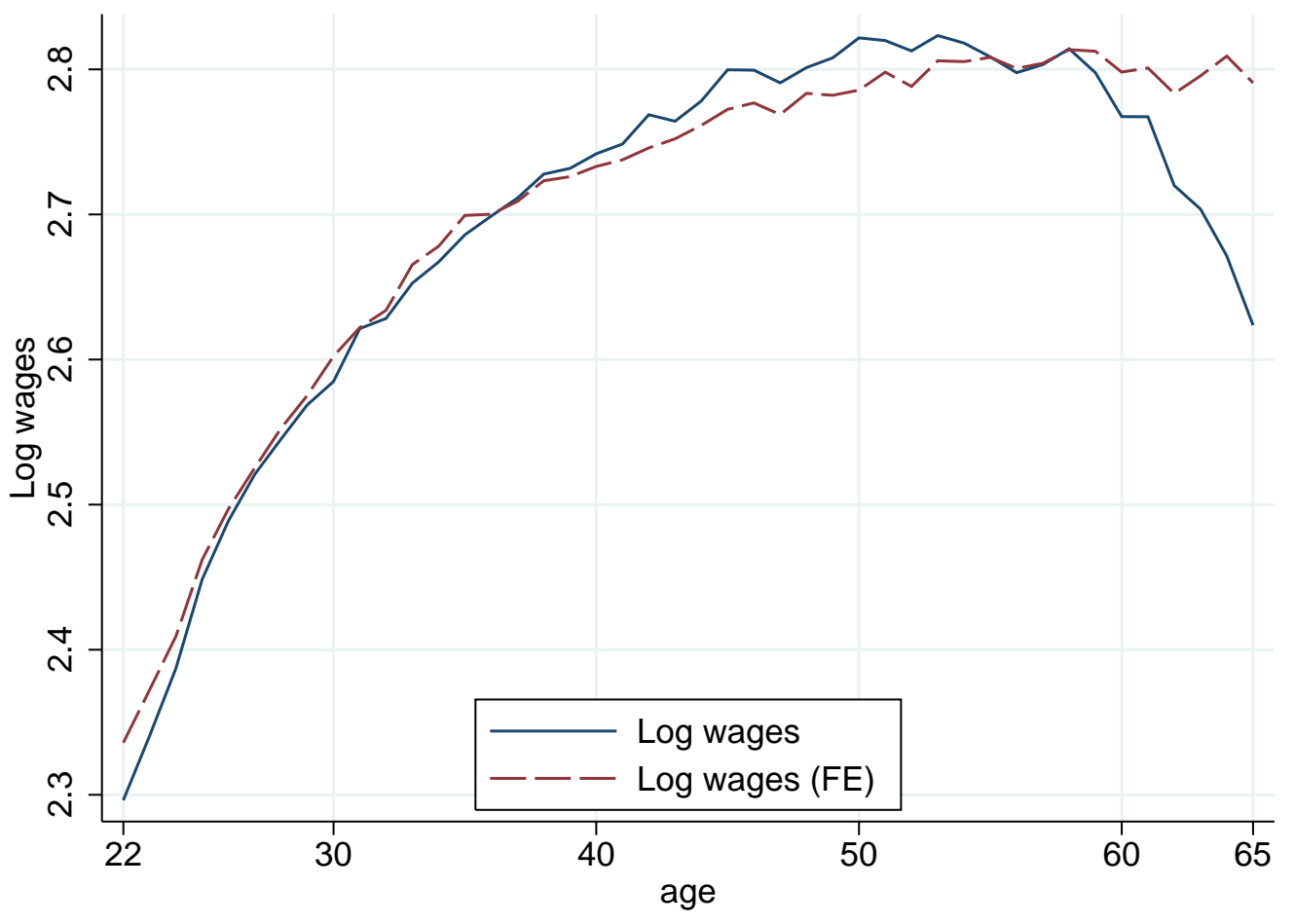


Figure 1c: Standard deviation of log wages—SIPP data

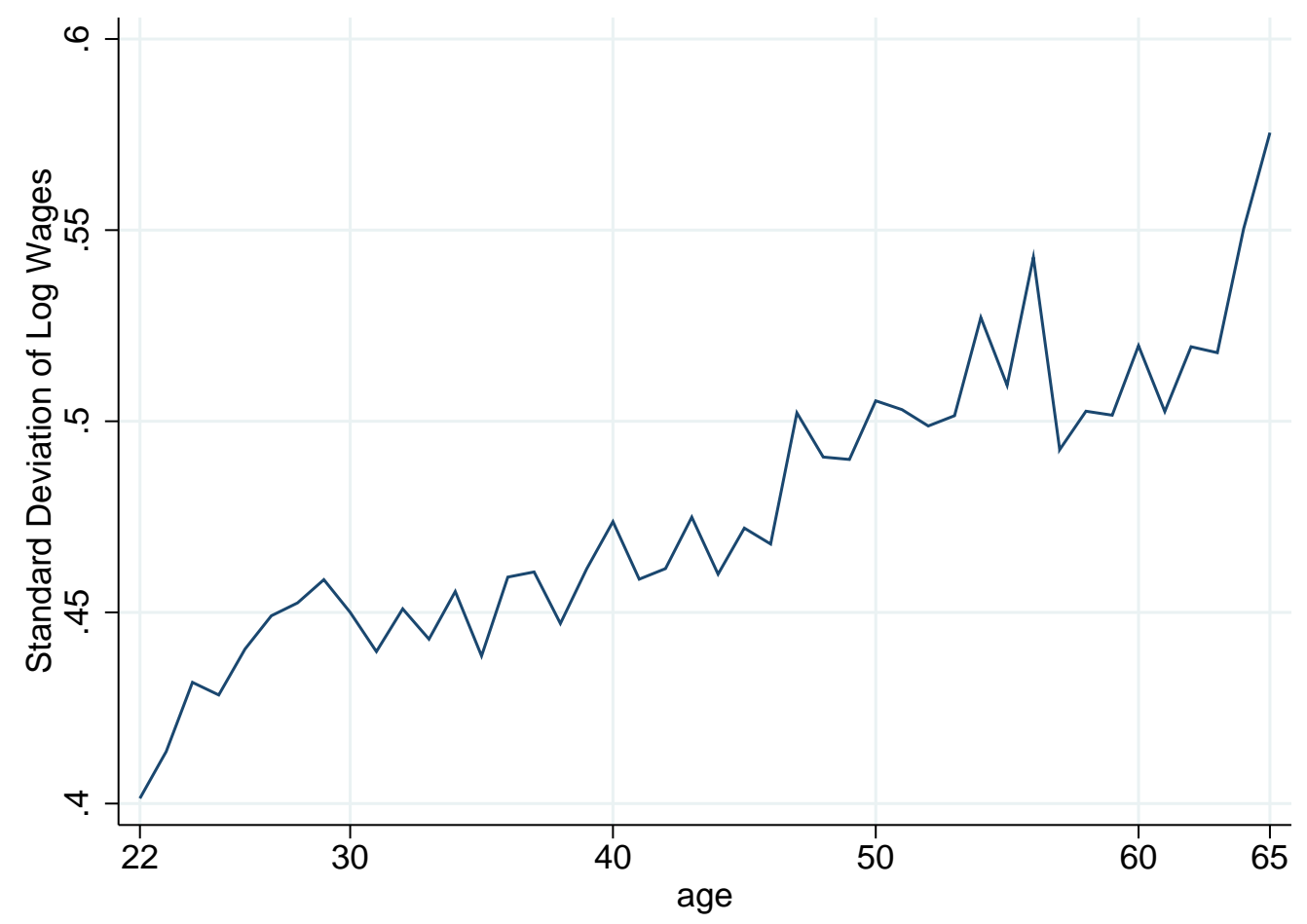

Figure 2: Log wage profiles of male high school graduates with and without controlling for individual fixed effects, CPS MORG and March data.

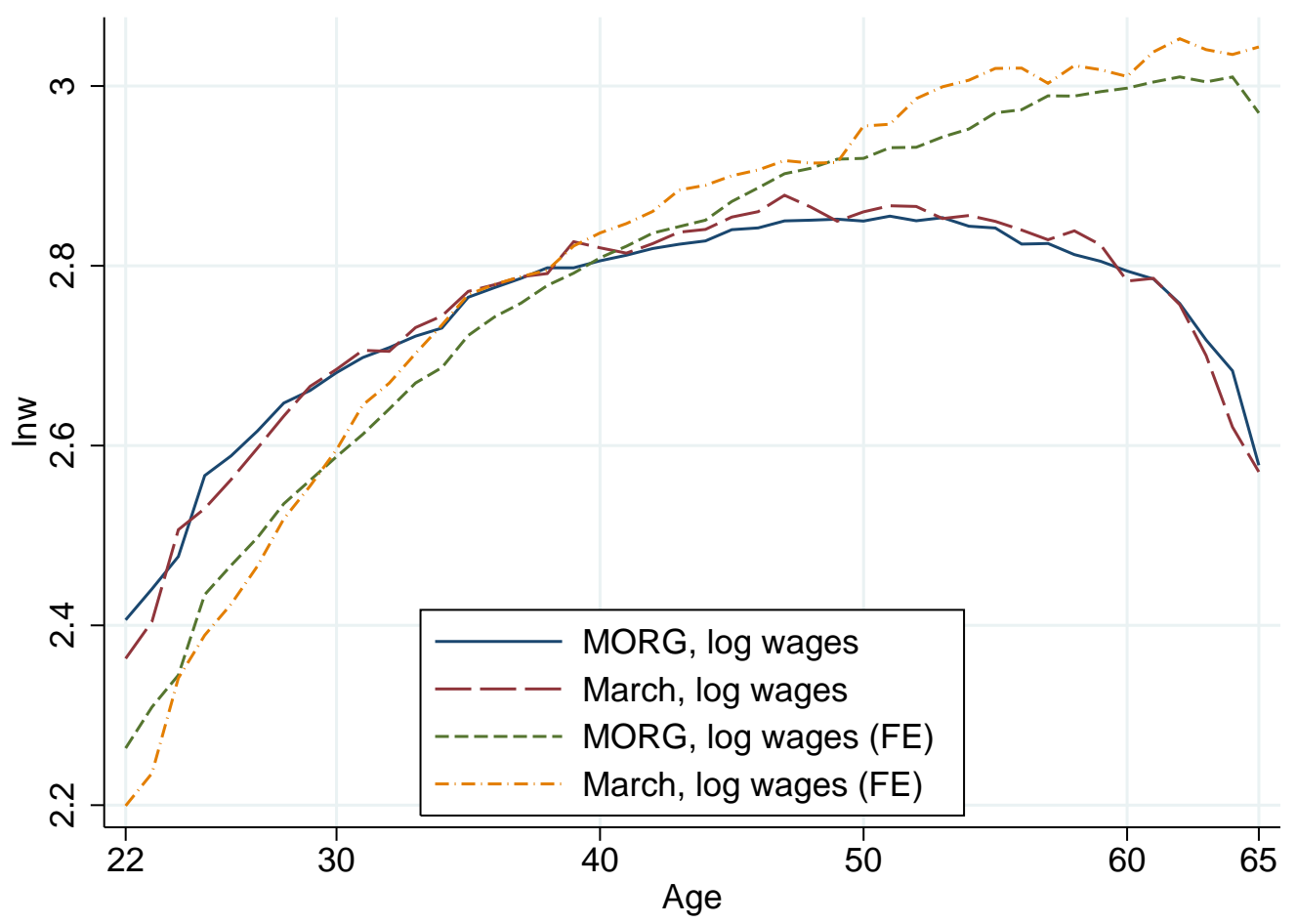


Figure 3a: Fit of model: labor force participation rate

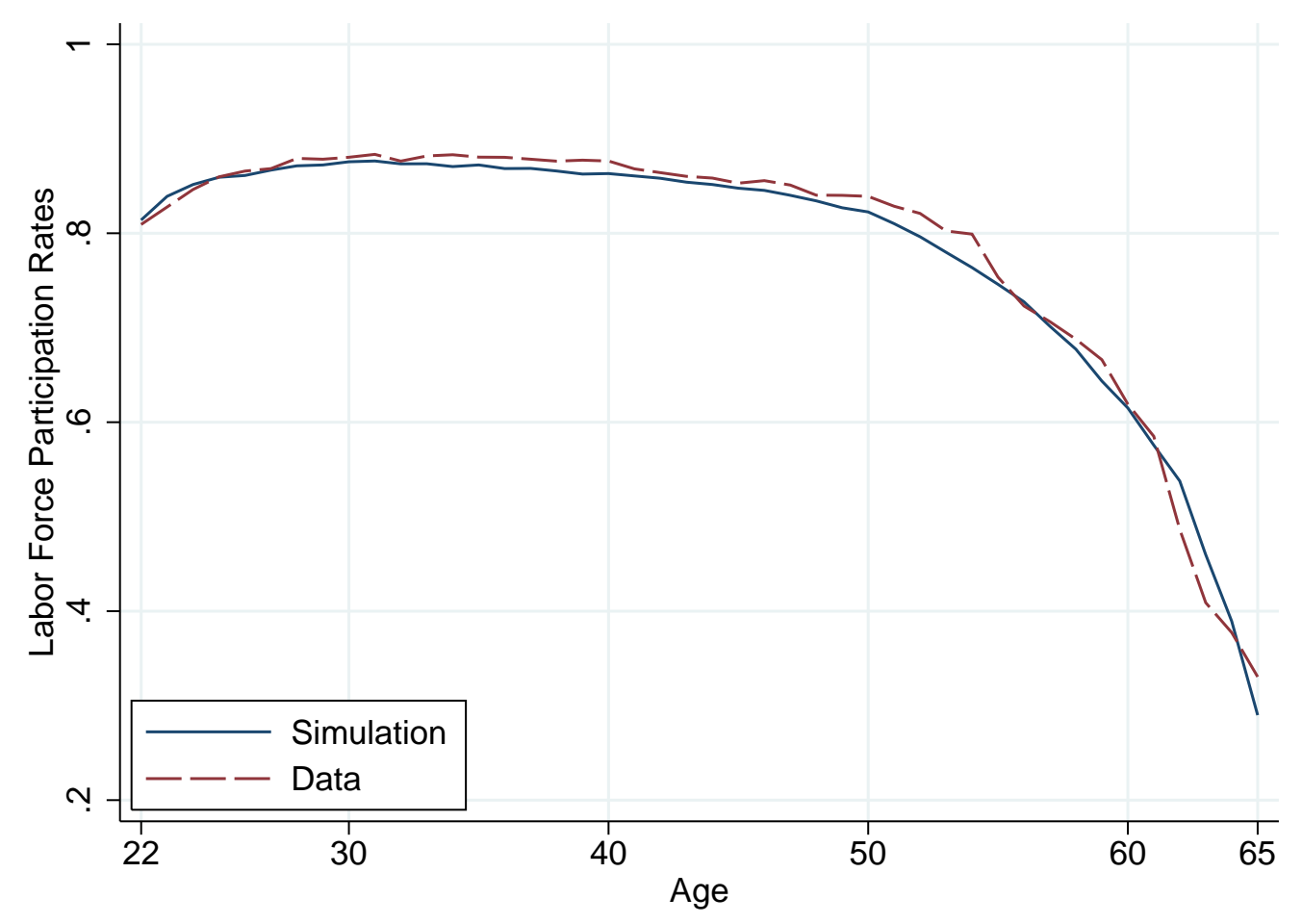

Figure 3b: Fit of model: log wages after controlling for individual fixed effects

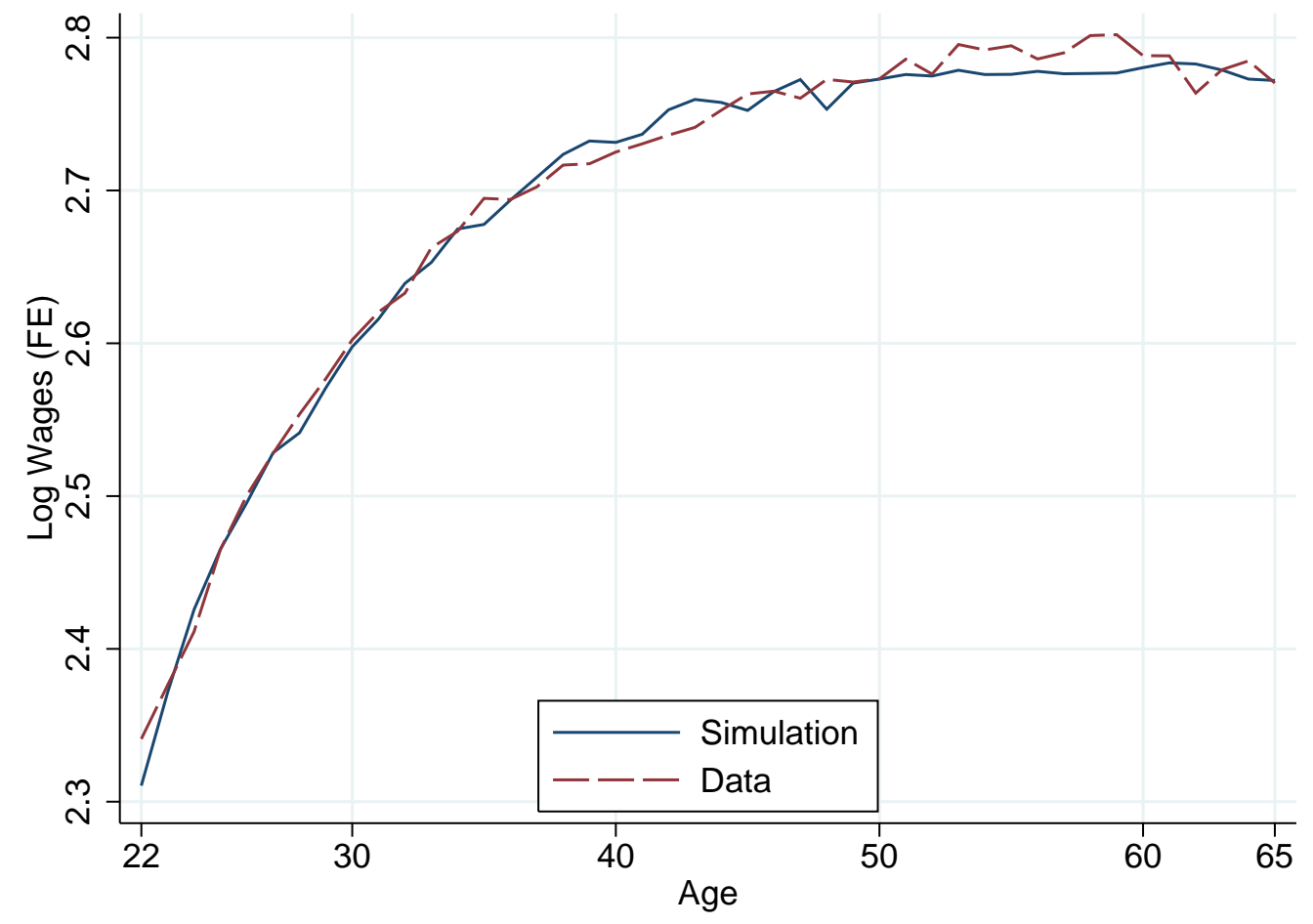


Figure 3c: Fit of model: log wages

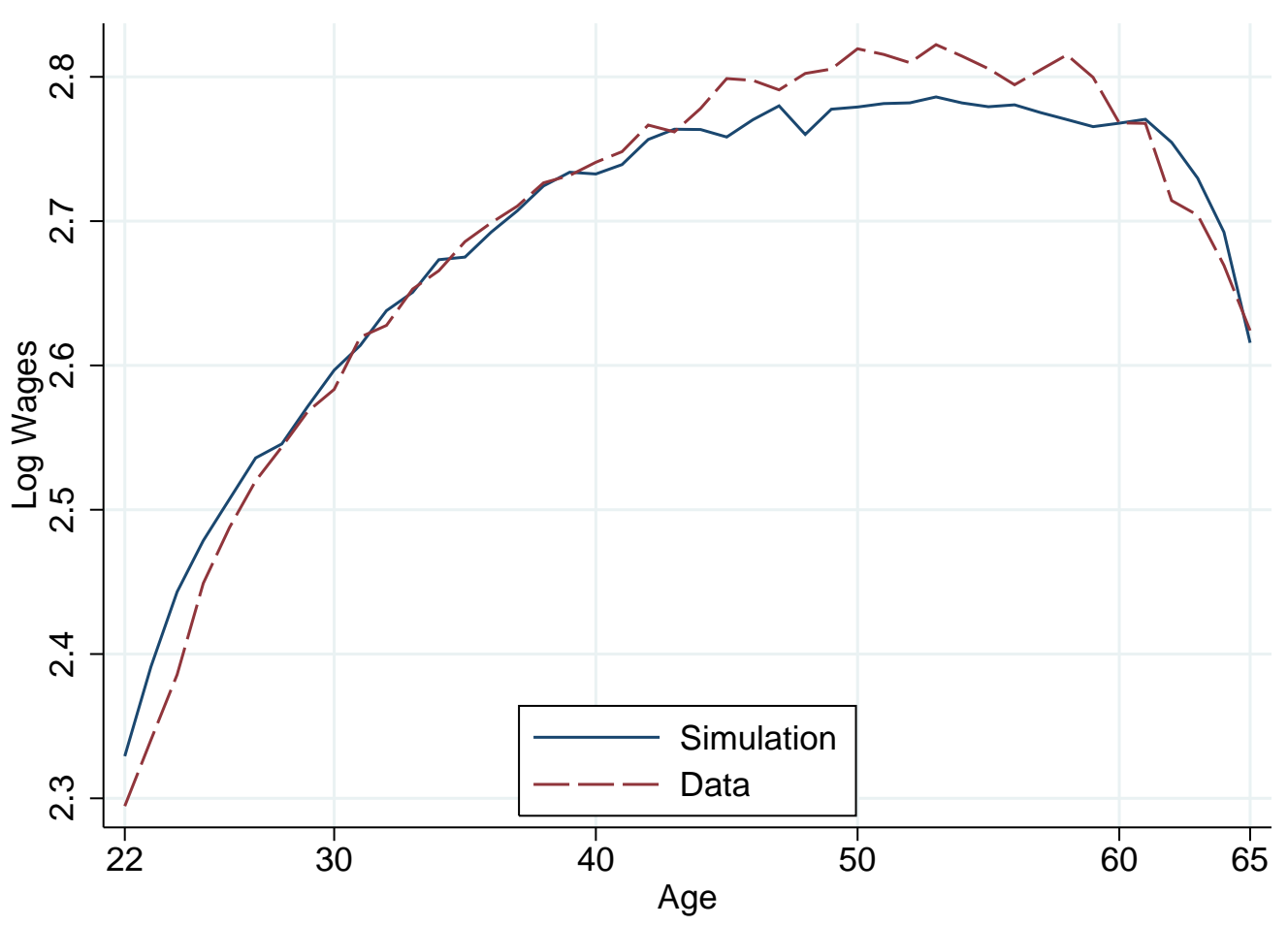

Figure 3d: Fit of model: standard deviations of log wages

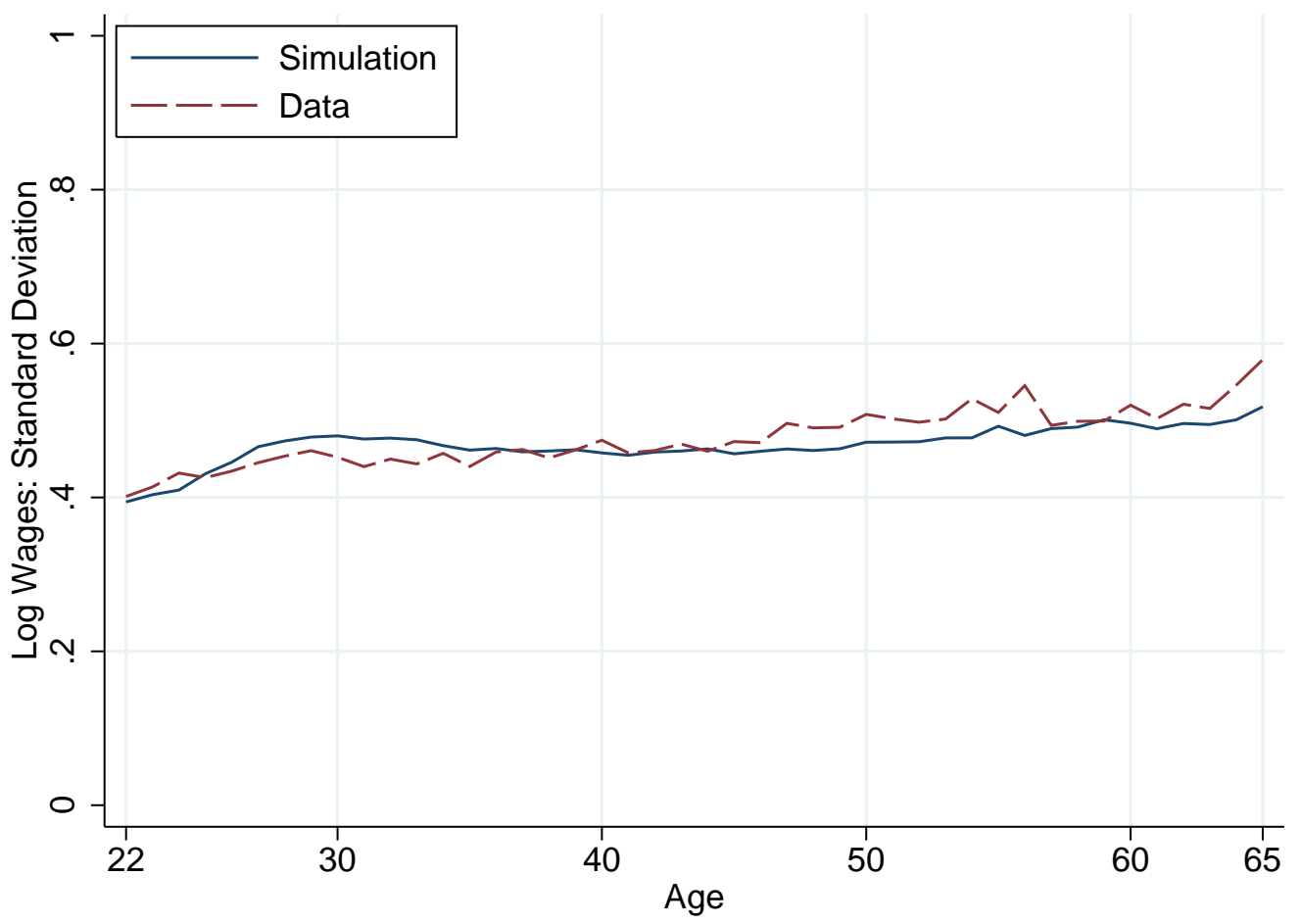


Figure 4a: Log wages and human capital

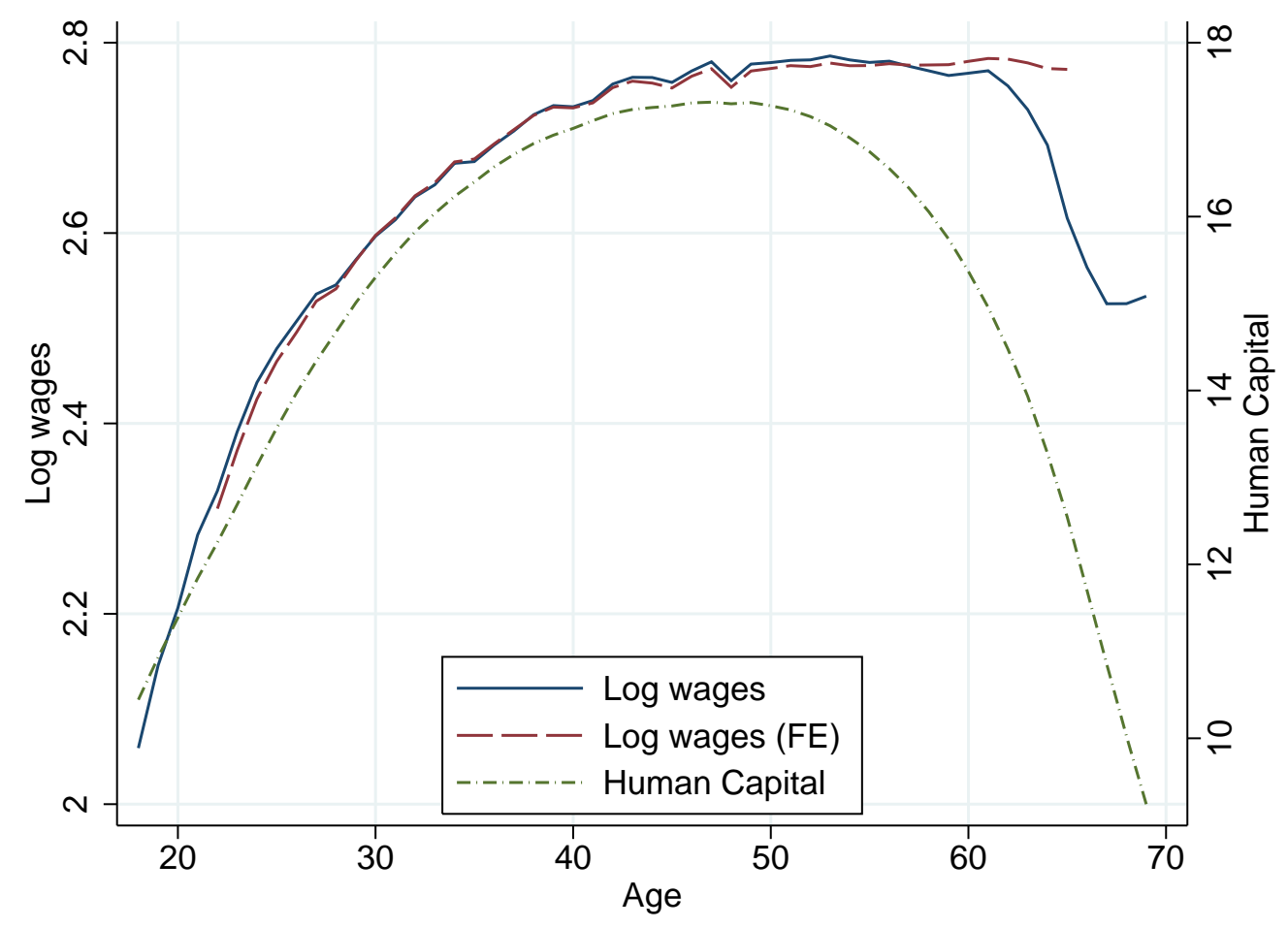

Figure 4b: Investment, and human capital

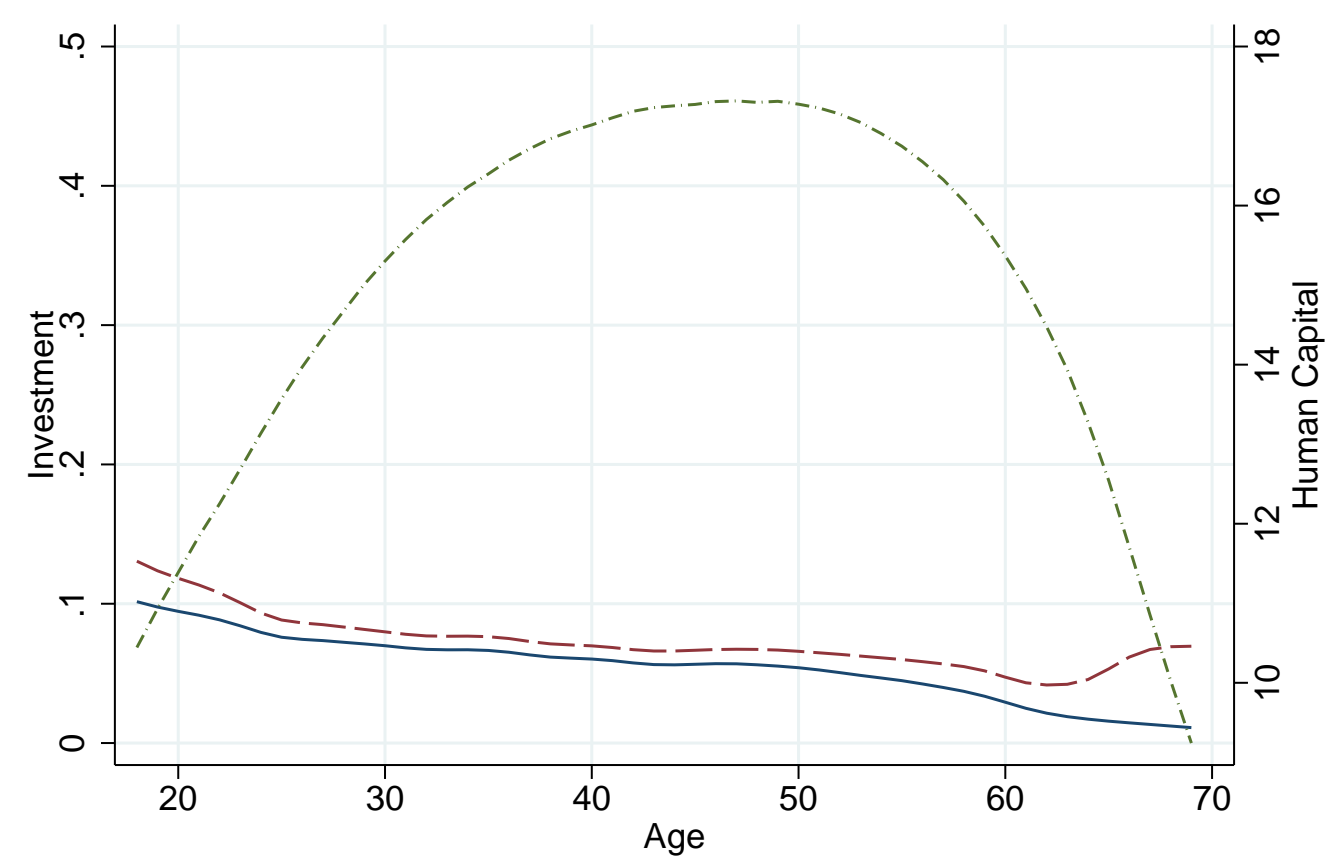

Investment --- Investment at work - - Human Capital 
Figure 5a: Fit of model with health

(i) Labor Force Participation Rates

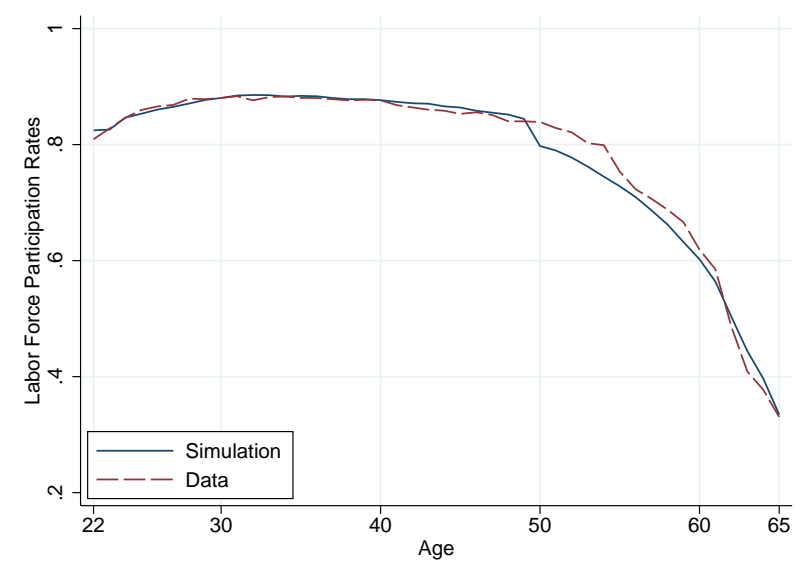

(iii) Log Wages \& Log Wages (FE)

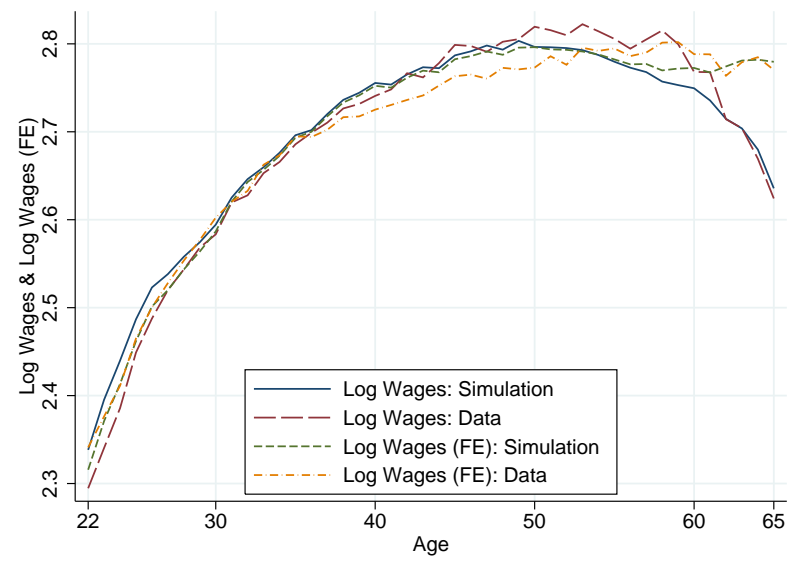

(ii) LFPR difference, good vs bad health

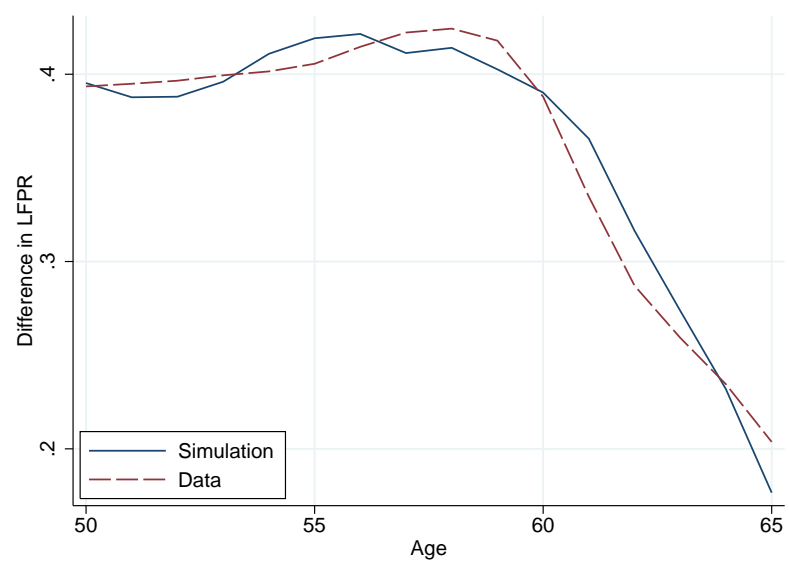

(iv) Standard Deviation of Log Wages

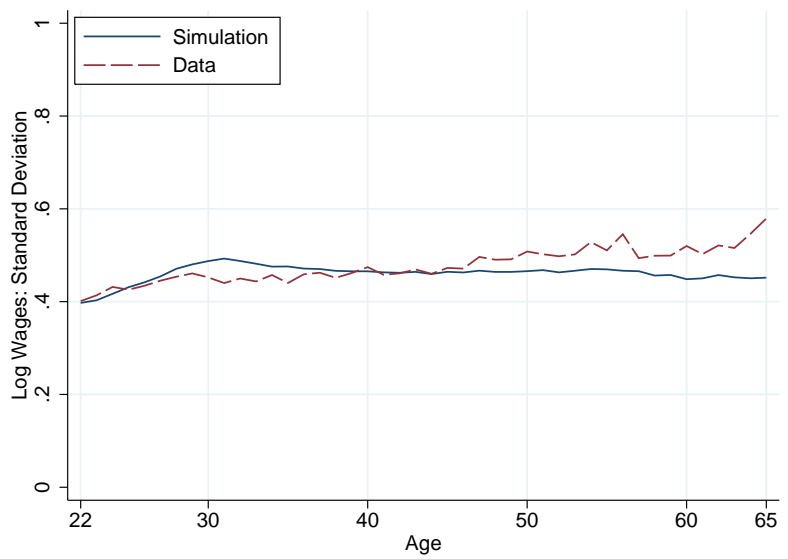

Figure 5b: Sensitivity to heath preferences: health status fixed and taste for leisure unchanged after age 50

(i) Labor Force Participation Rates

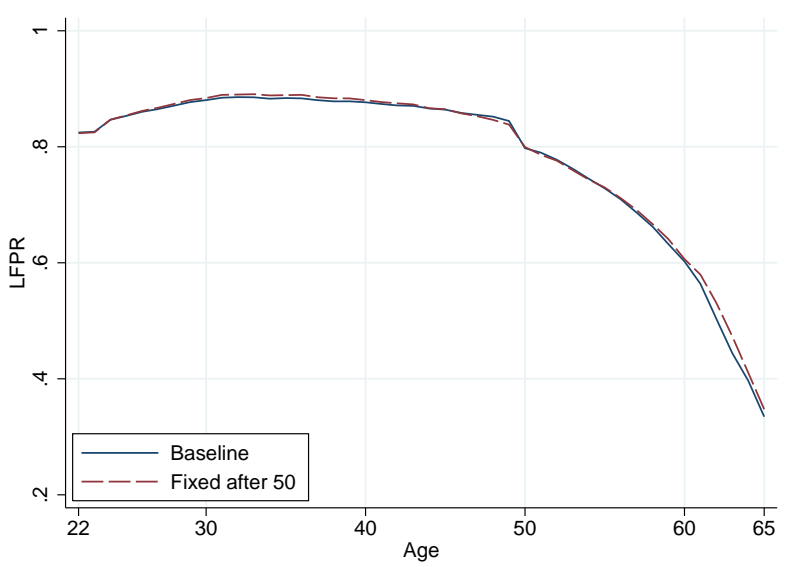

(ii) Human Capital Levels

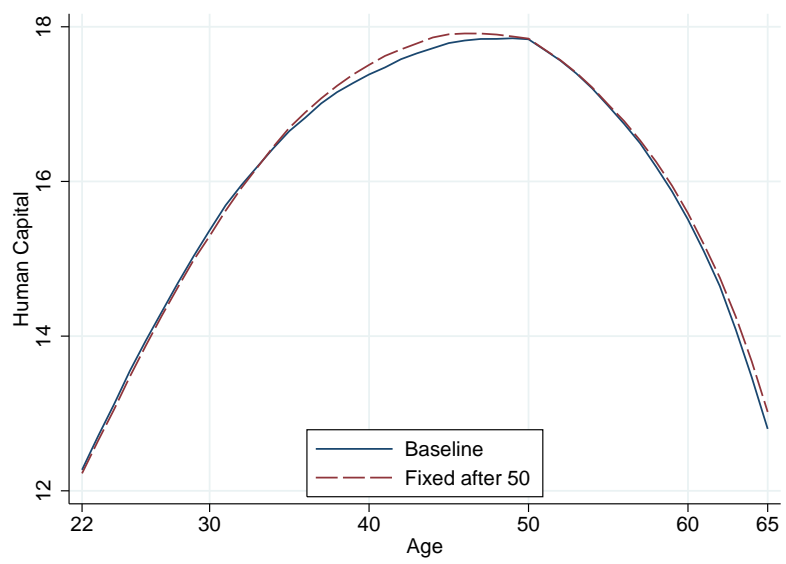


Figure 6a: [Baseline model] Policy experiments: reduce Social Security benefits

(i) Difference in Labor Force Participation Rates

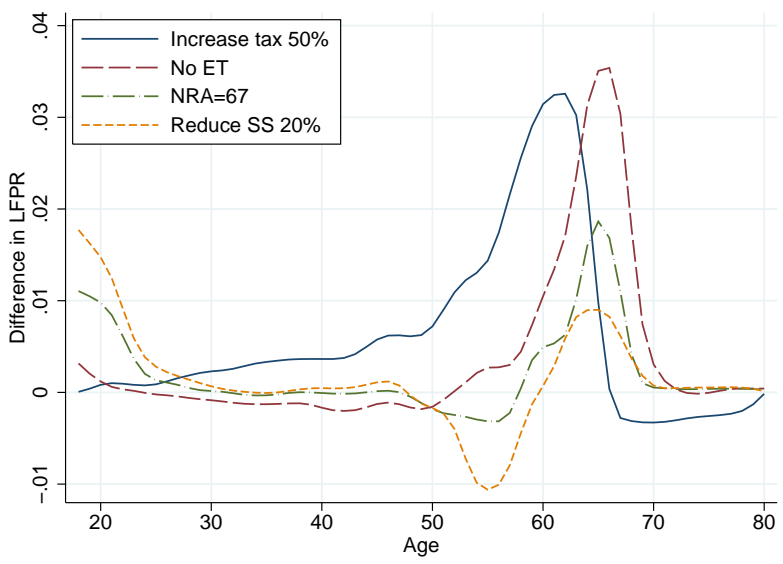

(iii) Difference in Investment

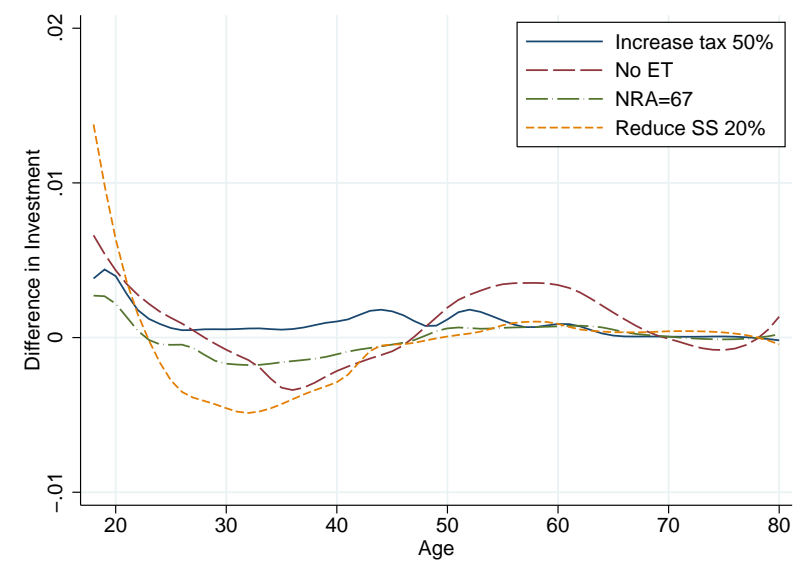

(ii) Difference in Log Wages

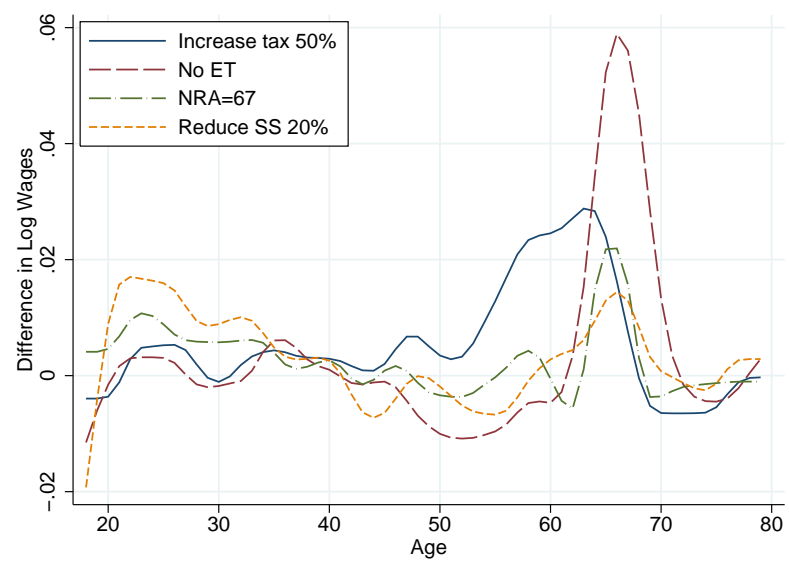

(iv) Difference in Human Capital

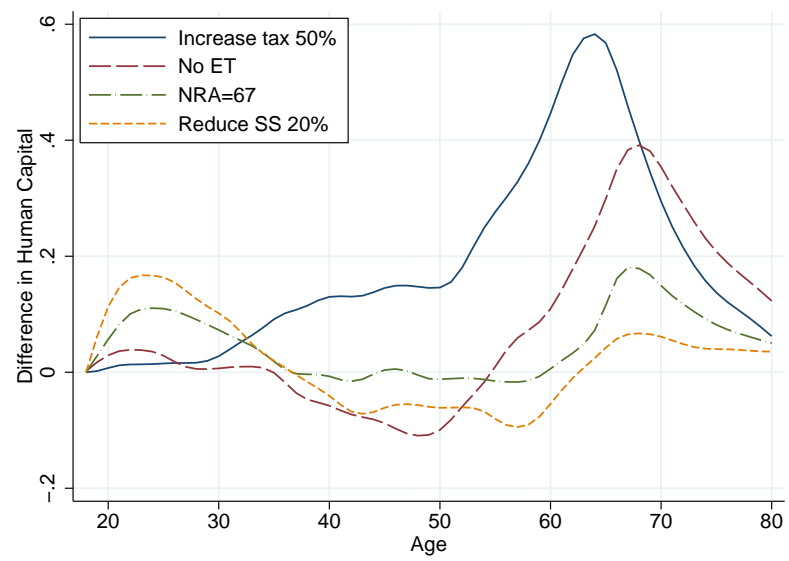


Figure 6b: [Baseline model] Policy experiments: remove Social Security taxes or benefits

(i) Difference in Labor Force Participation Rates

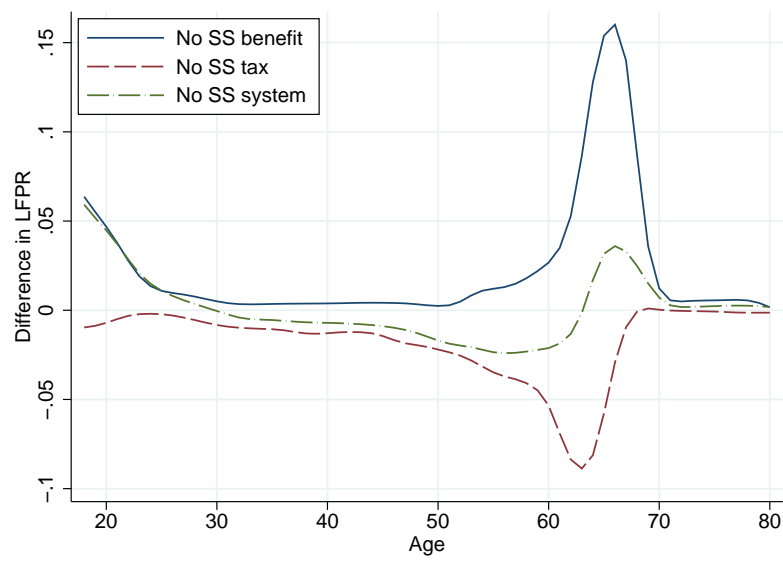

(iii) Difference in Investment

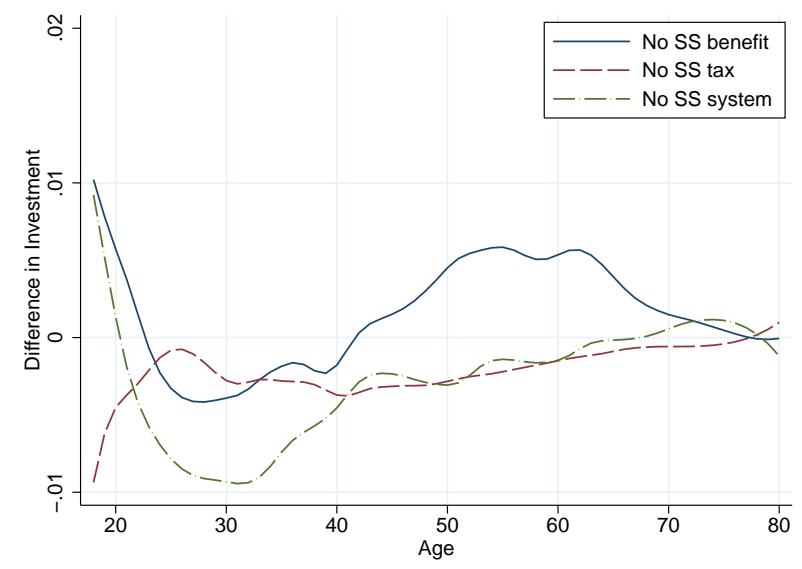

(ii) Difference in Log Wages

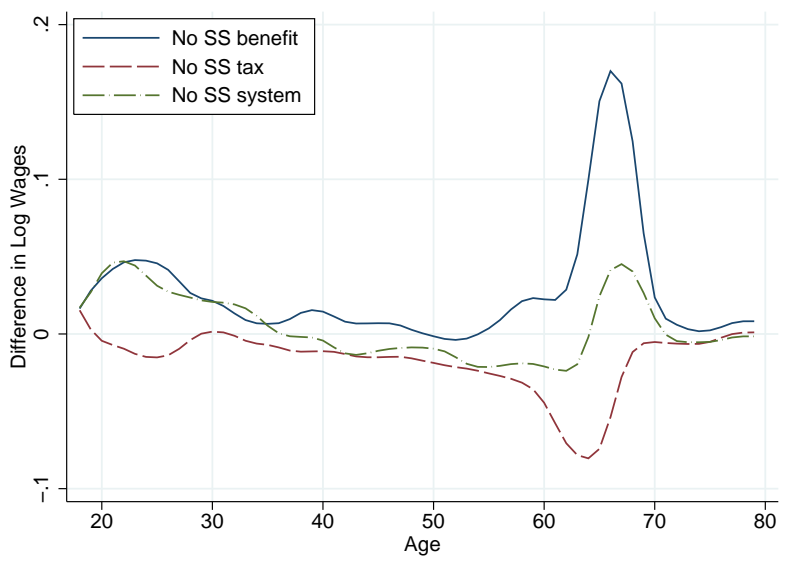

(iv) Difference in Human Capital

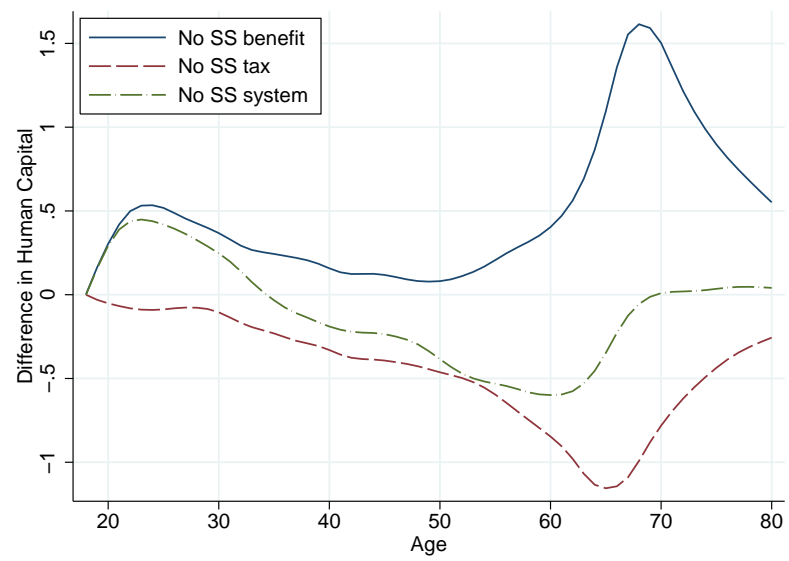




\section{References}

Aiyagari, S. Rao, "Uninsured Idiosyncratic Risk and Aggregate Saving," The Quarterly Journal of Economics, 1994, 109 (3), 659-684.

Ben-Porath, Yoram, "The Production of Human Capital and the Life Cycle of Earnings," Journal of Political Economy, August 1967, 75 (4), 352-365.

Blau, David, "Retirement and Consumption in a Life Cycle Model," Journal of Labor Economics, January 2008, 26 (1), 35-71.

- and Tetyana Shvydko, "Labor Market Rigidities and the Employment Behavior of Older Workers," Industrial and Labor Relations Review, April 2011, 64 (3), 464-484.

Blundell, Richard, Monica Costa Dias, Costas Meghi, and Jonathon Shaw, "Female Labour Supply, Human Capital and Welfare Reform," March 2015.

Browning, Martin, Lars Peter Hansen, and James J. Heckman, "Micro Data and General Equilibrium Models," Handbook of Macro Economics, 1999, 1, 525-602.

Casanova, Maria, “Happy Together: A Structural Model of Couples' Joint Retirement Choices," November 2010. Working paper.

_ , "Revisiting the Hump-Shaped Wage Profile," August 2013. Working paper.

Currie, Janet and Brigitte C Madrian, "Health, health insurance and the labor market," Handbook of labor economics, 1999, 3, 3309-3416.

DeNardi, Mariacristina, "Wealth Inequality and Intergenerational Links," The Review of Economic Studies, July 2004, 71 (3), 743-768.

Farber, Henry, “The Incidence and Costs of Job Loss: 1982-91," Brookings Papers: Microeconomics, 1993, pp. 73-132.

French, Eric, "The Effects of Health, Wealth and Wages on Labor Supply and Retirement Behavior," Review of Economic Studies, April 2005, 72 (2), 395-427.

- and John Bailey Jones, "The effects of Health Insurance and Self-Insurance on Retirement Behavior," Econometrica, May 2011, 79 (3), 693-732.

Gorlich, Dennis and Andries de Grip, "Human Capital Depreciation During Hometime," Oxford Economic Papers, 2009, 61, i98-i121. 
Gustman, Alan L. and Thomas L. Steinmeier, "A Structural Retirement Model," Econometrica, May 1986, 54 (3), 555-584.

Haan, Peter and Victoria Prowse, "Longevity, life-cycle behavior and pension reform," Journal of Econometrics, 2014, 178, 582-601.

Haley, William, "Estimation of the Earnings Profile from Optimal Human Capital Accumulation," Econometrica, 1976, 44 (6), 1223-1288.

Heckman, James J., "Estimates of a Human Capital Production Function Embedded in a Life-Cycle Model of Labor Supply," in N. Terleckyj, ed., Household production and consumption, Columbia University Press, 1975, pp. 99-138.

_ , "A Life-Cycle Model of Earnings, Learning, and Consumption," The Journal of Political Economy, August 1976, 84 (4), S11-S44.

_ , Lance J. Lochner, and Petra E. Todd, Earnings Functions, Rates of Return and Treatment Effects: The Mincer Equation and Beyond, Vol. 1, Amsterdam: North Holland,

_ , Lance Lochner, and Christopher Taber, "Explaining Rising Wage Inequality: Explanations With A Dynamic General Equilibrium Model of Labor Earnings With Heterogeneous Agents," Review of Economic Dynamics, 1998a, 1 (1), 1-58.

_ , _, and _ , "Tax Policy and Human-Capital Formation," American Economic Review: Papers and Proceedings, 1998b, 88 (2), 293-297.

_, , , and _, "Human Capital Formation and General Equilibrium Treatment Effects: A Study of Tax and Tuition Policy," Fiscal Studies, 1999, 20 (1), 25-40.

_ , _, and Ricardo Cossa, "Learning-by-doing vs. on-the-job training: Using variation induced by the EITC to distinguish between models of skill formation," in Edmund S. Phelps, ed., Designing inclusion: Tools to raise low-end pay and employment in private enterprise ,, Cambridge University Press 2003, pp. 74-130.

Hubbard, R. Glenn, Jonathan Skinner, and Stephen P. Zeldes, "Precautionary Saving and Social Insurance," The Journal of Political Economy, April 1995, 103 (2), 360-399.

Imai, Susumu and Michael P. Keane, "Intertemporal Labor Supply and Human Capital Accumlation," International Economic Review, May 2004, 45 (2), 601-641.

Johnson, Richard W and David Neumark, "Wage declines among older men," The Review of Economics and Statistics, 1996, pp. 740-748. 
Keane, Michael P. and Kenneth I. Wolpin, "The Career Decisions of Young Men," Journal of Political Economy, June 1997, 105 (3), 473-522.

Kunze, Astrid, "The Timings of Careers and Human Captial Depreciation," June 2002. IZA Working Paper No. 509.

Kuruscu, Burhanettin, "Training and Lifetime Income," American Economic Review, June 2006, 96 (3), 832-846.

Li, Hsueh-Hsiang, "The Effects of Human Capital Depreciation on Occupational Gender Segregation," May 2013.

Light, Audrey and Manuelita Ureta, "Early-Career Work Experience and Gender Wage Differentials," Journal of Labor Economics, 1995, 13 (1), 121-154.

Madrian, Brigitte C and Lars John Lefgren, "An approach to longitudinally matching Current Population Survey (CPS) respondents," Journal of Economic and Social Measurement, 2000, 26 (1), 31-62.

Manuelli, Rodolfo E., Ananth Seshadri, and Yongseok Shin, "Lifetime Labor Supply and Human Capital Investment," January 2012. Working paper.

Mincer, Jacob, "Investment in Human Capital and Personal Income Distribution," Journal of Political Economy, August 1958, 66 (4), 281-302.

- and Haim Ofek, "Interuppted Work Careers: Depreciation and Restoration of Human Capital," The Journal of Human Resources, 1982, 17 (1), 3-24.

- and Soloman Polachek, "Family Investments in Human Capital: Earnings of Women," Journal of Political Economy, 1974, 82 (2), s76-s108.

Neal, Derek, "The Complexity of Job Mobility among Young Men," Journal of Labor Economics, April 1999, 17 (2), 237-261.

Prescott, Edward C., Richard Rogerson, and Johanna Wallenius, "Lifetime aggregate labor supply with endogenous workweek length," Review of Economic Dynamics, 2009, $12,23-36$.

Rogerson, Richard and Johanna Wallenius, "Fixed Costs, Retirement and the Elasticity of Labor Supply," October 2010. mimeo, Arizona State University.

Rosen, Sherwin, "A Theory of Life Earnings," Journal of Political Economy, 1976, 84 (4), S45-S67. 
Ruhm, Christopher, "Are Workers Permanently Scarred by Job Displacement," American Economic Review, 1991, 81 (1), 319-324.

Rupert, Peter and Giulio Zanella, "Revisiting wage, earnings, and hours profiles," June 2012. Working paper.

Rust, John and Christopher Phelan, "How Social Security and Medicare Affect Retirement Behavior In a World of Incomplete Markets," Econometrica, July 1997, 65 (4), 781831.

Schmieder, Johannes, Till von Wachter, and Stefan Bender, "The Causal Effect of Unemploment Duratoin on Wages: Evidence from Unemployment Insurance Extensions," November 2014.

Shaw, Kathryn L., "Life-Cycle Labor Supply with Human Capital Accumulation," International Economic Review, May 1989, 30 (2), 431-456.

Taber, Christopher, "Tax Reform and Human Capital Accumulation: Evidence from an Empirical General Equilibrium Model of Skill Formation," Advances in Economic Analysis and Policy, 2002, 2 (1).

Topel, Robert H. and Michael P. Ward, "Job Mobility and the Careers of Young Men," The Quarterly Journal of Economics, May 1992, 107 (2), 439-479.

Wallenius, Johanna, "Human Capital Accumulation and the Intertemporal Elasticity of Substitution of Labor," September 2009. Working paper.

Weiss, Yoram, "The determination of lifecycle earnings: A survey," in Orley Ashenfelter and David Card, eds., Handbook of Labor Economics, Vol. 1, Amsterdam: North-Holland, 1986, pp. 603-640. 
Table A1: Wage income tax codes (in 2004\$).

\begin{tabular}{ccc}
\hline Marginal Tax Rate & Pre-tax $(Y)$ & Post-tax Income \\
\hline 0.0765 & $\leq 10,250$ & $0.9235 Y$ \\
0.1765 & $10,251-20,450$ & $9,465.88+0.8235(Y-10,250)$ \\
0.2265 & $20,451-49,150$ & $17,865.58+0.7735(Y-20,450)$ \\
0.3265 & $49,151-87,900$ & $40,065.03+0.6735(Y-49,150)$ \\
0.2645 & $87,901-110,750$ & $66,163.15+0.7355(Y-87,900)$ \\
0.2945 & $110,751-172,950$ & $82,969.33+0.7055(Y-110,750)$ \\
0.3445 & $172,951-329,350$ & $126,851.43+0.6555(Y-172,950)$ \\
0.3645 & $\geq 329,351$ & $229,371.63+0.6355(Y-329,350)$ \\
\hline
\end{tabular}

\section{Appendix}

\section{A Taxes}

We use tax codes in the year of 2004. There are two different kinds of taxes that the worker's wage income is subject to, namely the payroll taxes and the federal income taxes. We ignore the state income taxes. The payroll taxes include the Social Security portion, $6.2 \%$ capped at $\$ 87,900$, and the Medicare tax, $1.45 \%$ uncapped. The federal income taxes are progressive and we use the tax rules under head of household. The personal exemption for each person is $\$ 3,100$ and the standard deduction for head of household is $\$ 7,150$. These all together generate the tax codes used in the paper in Table A1.

\section{B Social Security}

We use most Social Security rules in the year of $2004 .^{29}$

\section{B.1 The Social Security Benefits}

The normal retirement age (NRA) is 65. The worker receives full Social Security benefits if he applies for the benefits at the NRA. The full retirement benefits are equal to the Primary Insurance Amount (PIA), which is a function of Average Indexed Monthly Earnings (AIME),

$$
\begin{aligned}
P I A= & 0.9 * \min \left\{b p_{1}, A I M E\right\}+0.32 * \min \left\{b p_{2}-b p_{1}, \max \left\{0, A I M E-b p_{1}\right\}\right\} \\
& +0.15 * \max \left\{0, A I M E-b p_{2}\right\},
\end{aligned}
$$

\footnotetext{
${ }^{29}$ Most of information about Social Security benefits in this section is extracted from http:/ / www.ssa.gov.
} 
where $\left(b p_{1}, b p_{2}\right)=(612,3689)$ where the dollar amounts are for 2004 .

The AIME is computed as the monthly average earning of the 35 years with highest inflation-adjusted earnings. Only earnings subject to the Social Security tax are used in the calculation and therefore AIME is capped. The included earning in a specific year is adjusted for wage inflation by multiplying the wage growth rate relative to the base year, which is at age 60 . The wage growth rate is calculated by dividing the average wage in the base year by the average wage in that specific year. Earnings after the base year are not adjusted. Interestingly, the wage growth rate of the national average wage index is very similar to the growth rate of CPI-U after Year 1969, as shown in Figure B1, so we ignore the small difference between these two and use the real wages to update AIME without adjustment.

Computing exact AIME requires keeping tracking of the worker's earning history, which is computationally infeasible. Instead we apply an approximating method, taking into account the wage growth pattern over the life-cycle,

$$
A I M E_{t+1}=A I M E_{t}+\max \left\{0, \frac{s s e_{t}}{35 \times 12}-\text { share }_{\min }(t) \cdot A I M E_{t}\right\}
$$

where $s s e_{t}=\min \left\{H_{t}\left(1-\ell_{t}\right)\left(1-I_{t}\right), s \bar{s} e\right\}$ is included earning, capped at $s \bar{s} e=\$ 87,900$. The share $_{\text {min }}$ is the share of minimum wage in AIME. Figure B2 lists the estimated share $_{\text {min }}(t)$ from CPS data for age 52 to 76 , assuming the starting working age of 16 , and share $_{\min }(t<52)=0$.

The early retirement age (ERA) is 62 . Starting from ERA, the worker is eligible to receiving the Social Security benefits at a reduced level. In this case, the benefit is reduced $5 / 9$ of one percent for each month before NRA, or $6.67 \%$ per year, up to three years. Beyond three years, the benefit is reduced $5 / 12$ of one percent per month or $5 \%$ per year.

On the other hand, delayed receiving Social Security benefits after the NRA increases benefits. The delayed retirement credit (DRC) of $6 \%$ is given to the applicant for each delayed year up to age $69 .{ }^{30}$ No DRC is given for applicants at age 70 or older.

\section{B.2 The Social Security Earnings Test}

We use the Social Security earnings test rules in 1999. ${ }^{31}$ The Social Security benefits could be withheld partly or totally if the worker is earning income while taking the Social Security benefits at ages before 70 .

\footnotetext{
${ }^{30}$ The 6\% DRC is for cohorts born between 1935 and 1936 (inclusive). The DRC varies from 3\% for cohorts born in 1924 or earlier to $8 \%$ for cohorts born in 1943 or later. In between, it increases by $0.5 \%$ every two years.

${ }^{31}$ Before 2000, the earnings test applies to ages before 70 . Since 2000, the earnings test is eliminated after reaching NRA.
} 
For beneficiary under age $65, \$ 1$ of benefits for every $\$ 2$ of earnings in excess of the exempt amount under 1999 rules ( $\$ 10,885$ in 2004 dollars) is withheld. The benefit withholding rate for those aged 65-69 is $\$ 1$ of benefits for every $\$ 3$ of earnings in excess of the exempt amount (\$17,575 in 2004 dollars).

If a whole year's worth of benefits is withheld between ages 62 to 64 , benefits in the future will be raised by $6.7 \%$ each year. If the benefit is withheld between age 65 to 69 , the future benefits will be raised by $6.0 \%$. Given our terminal age at 80 , it is favorable for individuals aged 62 to 64 but not actuarially fair for individuals aged 65 or older.

\section{B.3 Taxable Social Security Benefits}

The Social Security benefits are not taxable if it is the only income. If there is other income, compute "total income" as the sum of half of the benefits and all other income. If total income is no more than the base amount $(\$ 25,000$ for head of household) then no benefits are taxable. If total income is higher than $\$ 34,000$ then up to $85 \%$ of the benefits could be taxable ${ }^{32}$. Assume the Social Security benefits are $y_{s s}$ and all the other income is $y_{0}$, the taxable part of Social Security benefits is calculated as

$$
y_{s s, t a x a b l e}=\left\{\begin{aligned}
0, & \text { if } y_{o}=0 \text { or } y_{0}+\frac{y_{s s}}{2} \leq 25000 \\
\min \begin{cases}0.85 y_{s s}, \frac{1}{2} \min \left\{y_{s s}, y_{o}+\frac{y_{s s}}{2}-25000,9000\right. \\
\quad+0.85 \max \left\{0, y_{0}+\frac{y_{s s}}{2}-34000\right.\end{cases} & \\
& \text { otherwise. }
\end{aligned}\right.
$$

Figure B1: Relative (to Year 2004) indices of National Average Wage Index and CPI-U.

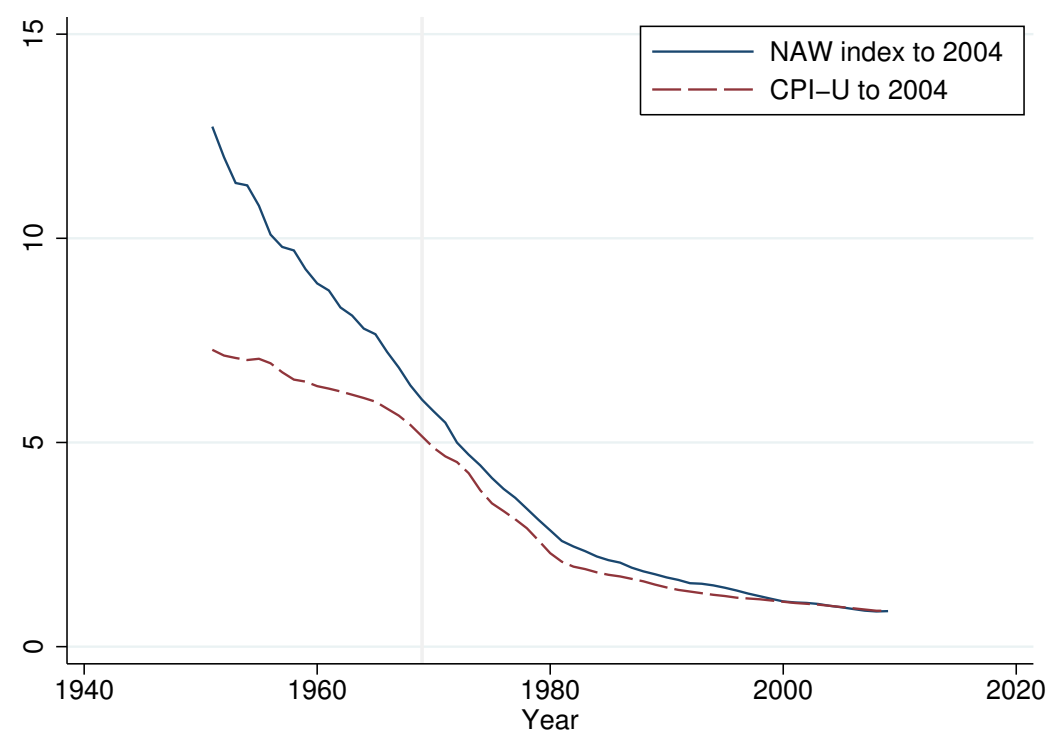

\footnotetext{
${ }^{32}$ We use the "head of household" which is similar to "single".
} 
Figure B2: Share of minimum wage on AIME, assuming starting working from age 16. CPS data.

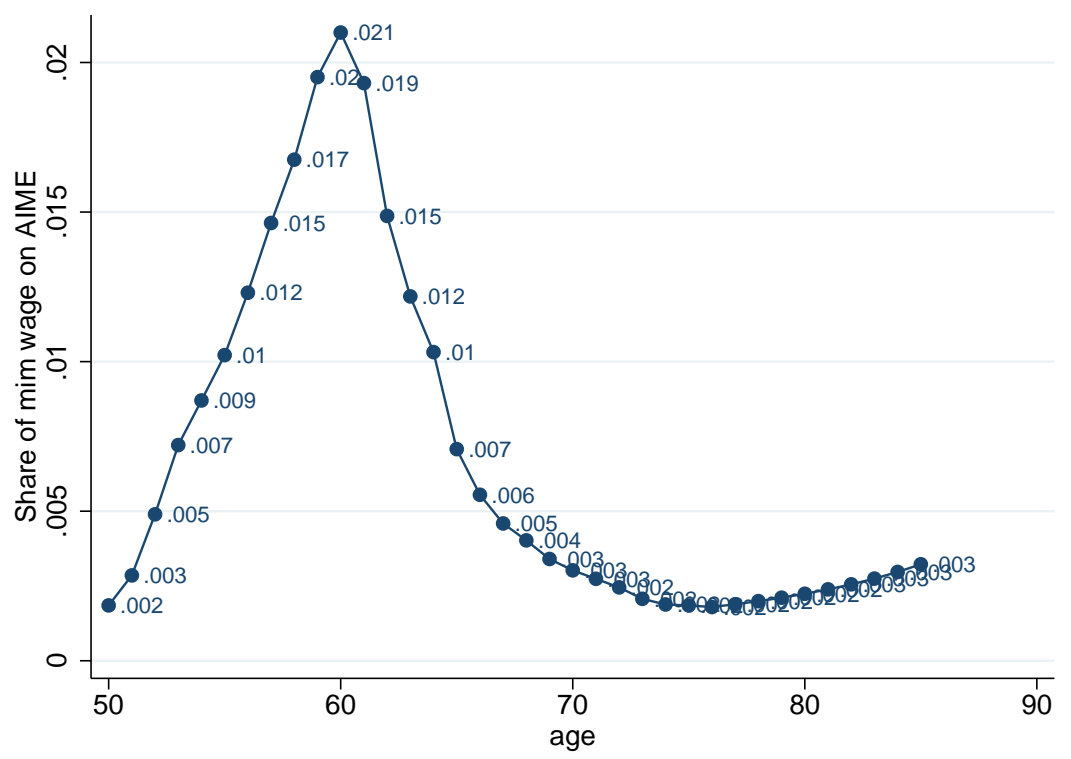

